\title{
Convectively coupled Kelvin and easterly waves in a regional climate simulation of the tropics
}

\author{
Stefan N. Tulich · George N. Kiladis • \\ Asuka Suzuki-Parker
}

Received: 30 April 2009/ Accepted: 22 October 2009/Published online: 14 November 2009

(C) Springer-Verlag 2009

\begin{abstract}
This study evaluates the performance of a regional climate model in simulating two types of synoptic tropical weather disturbances: convectively-coupled Kelvin and easterly waves. Interest in these two wave modes stems from their potential predictability out to several weeks in advance, as well as a strong observed linkage between easterly waves and tropical cyclogenesis. The model is a recent version of the weather research and forecast (WRF) system with 36-km horizontal grid spacing and convection parameterized using a scheme that accounts for key convective triggering and inhibition processes. The domain spans the entire tropical belt between $45^{\circ} \mathrm{S}$ and $45^{\circ} \mathrm{N}$ with periodic boundary conditions in the east-west direction, and conditions at the meridional/lower boundaries specified based on observations. The simulation covers 6 years from 2000 to 2005, which is long enough to establish a statistical depiction of the waves through space-time spectral filtering of rainfall data, together with simple lagged-linear regression. Results show that both the horizontal phase speeds and three-dimensional structures of the waves are qualitatively well captured by the model in comparison to observations. However, significant biases in wave activity are seen, with generally overactive easterly
\end{abstract}

S. N. Tulich

CIRES, University of Colorado, Boulder, CO, USA

S. N. Tulich

NCAR, Boulder, CO, USA

S. N. Tulich $(\bowtie) \cdot$ G. N. Kiladis

CIRES-NOAA/ESRL R/PSD1, 325 Broadway,

Boulder, CO, USA

e-mail: stefan.tulich@noaa.gov

A. Suzuki-Parker

Georgia Institute of Technology, Atlanta, GA, USA waves and underactive Kelvin waves. Evidence is presented to suggest that these biases in wave activity (which are also correlated with biases in time-mean rainfall, as well as biases in the model's tropical cyclone climatology) stem in part from convection in the model coupling too strongly to rotational circulation anomalies. Nevertheless, the model is seen to do a reasonable job at capturing the genesis of tropical cyclones from easterly waves, with evidence for both wave accumulation and critical layer processes being importantly involved.

Keywords Convectively coupled equatorial waves . Easterly waves - Kelvin waves - Regional climate modeling - Tropical climate - Tropical cyclones . Tropical cyclogenesis

\section{Introduction}

The tropical atmosphere is found to support a broad spectrum of zonally-propagating wave-like disturbances in both cloudiness and circulation. Relevant examples include convectively coupled Kelvin waves with periods of 3-10 days (Takayabu and Murakami 1991; Straub and Kiladis 2002), easterly waves or tropical depression-type disturbances with periods of 4-7 days (Chang 1970; Reed et al. 1977), and the planetary-scale Madden-Julian oscillation (MJO) with a period of 30-60 days (Madden and Julian 1994). Such waves can often be tracked for many days (sometimes even traveling around the globe) and constitute an important predictable component of mediumto extended-range weather in the tropics (Wheeler and Weickmann 2001; Miura et al. 2007; Mapes et al. 2008) and extratropics, via Rossby-wave teleconnections (Ferranti et al. 1990; Hendon et al. 2000). Yet current state-of-the-art 
global climate models are known to poorly simulate these waves (Slingo et al. 1996; Lin et al. 2006; Ringer et al. 2006; Yang et al. 2009; Straub et al. 2009).

While a variety of factors could be involved, there is growing evidence that deficiencies in model convective parameterization schemes are primarily responsible for this poor simulation of tropical waves. A telling example is the study by Khairoutdinov et al. (2008) who replaced the standard convection scheme of the National Center for Atmospheric Research (NCAR) Community Atmosphere Model (CAM) with a series of two-dimensional (2D) cloud-resolving models (CRMs), one for each grid box in the CAM. Results showed a dramatic improvement in the CAM's simulation of convectively-coupled Kelvin waves and the MJO, the latter of which was virtually absent from the standard CAM formulation. However, these improvements came at a considerable computational expense; the cost of running the "super-parameterized" CAM was reported to be roughly 200 times greater than running the standard CAM (Khairoutdinov et al. 2005). Moreover, such coarse-resolution models cannot directly address one of the most pressing scientific questions facing society today, namely, whether the intensity and occurrence rate of tropical cyclones (TCs) will change in a warming world.

Driven largely by this last point, scientists at NCAR recently used the weather research and forecast (WRF) model to perform a pair of multiyear simulations of the global tropics at 36-km horizontal grid spacing, with periodic boundary conditions in the zonal direction and meridional/lower boundary conditions specified based on observations. These novel "channel" simulations were made as first step towards a broader ongoing effort at NCAR of developing a global, coupled ocean-atmosphere model with local mesh refinement capabilities, so that studies of regional/global climate can be performed using a single framework. The WRF tropical channel model can thus be thought of as type of nested regional climate model (NRCM), whereby observational nudging at the boundaries serves as one-way driving of the NRCM by a "perfect" model of the rest of the atmosphere (and oceans).

Meanwhile other modeling centers have started to perform short-term $[O(10$-year $)]$ global climate simulations with horizontal grid spacings comparable to the WRF channel model (e.g., Chauvin et al. 2006; Oouchi et al. 2006; Bengtsson et al. 2007; Lau and Ploshay 2009). A distinct advantage of all of these high-resolution models is their ability to at least partially resolve key mesoscale circulations and heating processes associated with organized convective cloud systems (cf. Mapes 2000; Tulich et al. 2007; Tulich and Mapes 2008). On the other hand, the horizontal grid spacing of these models is still too coarse to resolve convective-scale circulations and heating processes, so some type of parameterization is needed. The
WRF tropical channel model is unique in this regard in that its convective parameterization, based on the schemes of Kain (2004) and Kain and Fritsch (1993), is specifically designed for models with mesoscale $[O(10-\mathrm{km})]$ grid spacing, and thus accounts for key convective inhibition and triggering processes (cf. Tulich and Mapes 2009; Kuang 2009).

This study examines the ability of the WRF tropical channel model to simulate two types of convectively-coupled synoptic wave disturbances: Kelvin and easterly waves. Interest in these two wave modes stems from their central role in determining the day-to-day weather of the tropics, as well as a strong observed linkage between easterly waves and TC genesis (e.g., Landsea 1993; Chen et al. 2008). The ability of the model to capture the lowerfrequency MJO, while also of interest, is considered only briefly here-more detailed assessments can be found in Caron (2009) and Ray et al. (2009).

The organization of this paper is as follows. The next section briefly describes the experiment setup and observational data used for model evaluation. Section 3 then gives an overview of the simulated versus observed spacetime variability of rainfall, followed by detailed evaluations of the simulated Kelvin and easterly waves in Sects. 4 and 5, respectively. Section 5 also evaluates the statistical relationship between easterly waves and TC genesis. This study's main findings are summarized and discussed in Sect. 6.

\section{Experiment and observational data}

\subsection{Experiment description}

The WRF channel model was used to perform a pair of multiyear simulations of the global tropics, each with lower oceanic boundary conditions specified using observed monthly sea-surface temperatures (SSTs; linearly interpolated to 6-h increments) and with meridional boundary conditions specified using six-hourly model reanalysis data (see Holland et al. 2009 for further details). The two runs together span the 10-year period, 1996-2005, but each has slightly different domain/grid configurations. In particular, the first run (covering the 5-year period, 1996-2000) has meridional boundaries at $30^{\circ} \mathrm{S}$ and $45^{\circ} \mathrm{N}$, with 35 vertical levels, ranging from the surface to pressure $p=50 \mathrm{hPa}$. Meanwhile, the second run (covering the 6-year period, $2000-2005$ ) has meridional boundaries at $45^{\circ} \mathrm{S}$ and $45^{\circ} \mathrm{N}$, with 51 vertical levels, ranging from the surface to $p$ $=10 \mathrm{hPa}$. Most of the results of this study were found to be independent of these changes in model configuration, however, we restrict our attention to the second run, for brevity. 
Post-processing of the model output consisted of vertically interpolating six-hourly winds, temperature, etc. from the native sigma-coordinate system of the model to a set of 38 pressure levels, with finer resolution near the top and bottom boundaries. To further expedite the analysis (and reduce storage requirements), these interpolated data were coarse-grained from $36-$ to $108-\mathrm{km}$ grid spacing in the horizontal (roughly $1^{\circ}$ in the tropics).

\subsection{Observational datasets}

Three sets of observational data were used to evaluate the WRF channel model's simulation of convectively-coupled tropical waves: (1) the Tropical Rainfall Measuring Mission (TRMM) 3B42 product (Huffman et al. 2007), (2) the Japanese 25-year Reanalysis (JRA-25; Onogi et al. 2007), and (3) the University of Wyoming's (UWYO's) atmospheric sounding archive. Brief descriptions of these various data are given below.

1. TRMM $3 B 42$ The TRMM 3B42 product consists of three-hourly satellite-based estimates of rainfall on a uniform $0.25^{\circ} \times 0.25^{\circ}$ latitude-longitude grid. The data are obtained by merging passive microwave estimates of rainfall together with geostationary infrared radiance (IR) data, as well as surface rain gauge observations (see Huffman et al. 2007 for further details). The data are currently available from the present back to 1 January 1998, but here the focus is mainly on the 2000-2005 period of the second WRF channel run. To ensure "apples-to-apples" comparisons between the WRF output and observations, the TRMM data were coarse-grained from three- to sixhourly in time and from $0.25^{\circ}$ to $1^{\circ}$ in space.

2. JRA-25 The JRA consists of six-hourly global atmospheric fields obtained using the Japanese Meteorological Association (JMA) numerical assimilation and forecast system. All fields are defined on a $1.25^{\circ} \times 1.25^{\circ}$ latitude-longitude grid, which is comparable to the coarse-grained WRF output examined here. Onogi et al. (2007) provide evidence that the JRA is superior to other reanalyses in terms of capturing observed tropical rainfall variability, which is one of the reasons it was chosen for this study.

3. UWYO sounding archive Routine soundings for numerous stations around the globe are available from the UWYO sounding archive, including two tropical island stations examined here: Majuro $\left(171^{\circ} \mathrm{E}, 7^{\circ} \mathrm{N}\right)$ and Yap $\left(138^{\circ} \mathrm{E}, 9.5^{\circ} \mathrm{N}\right)$. Twice-daily soundings for these two stations were analysed for the period 19992007. Prior to analysis, each sounding was interpolated to a set of 24 pressure levels between the surface and $p$ $=25 \mathrm{hPa}$.

\section{Space-time variability of rainfall}

Observations show a strong linkage between the timemean distribution of convective heating (using rainfall here as a proxy) and the overall level (and type) of transient convective wave activity. For example, easterly waves are typically most active during boreal summer when convection is generally located well north of the equator (Serra et al. 2008; Magnusdottir and Wang 2008). Meanwhile, Kelvin waves are typically most active during boreal spring when convection is generally closest to the equator (Roundy and Frank 2004). This section begins with an assessment of the time-mean distribution of rainfall simulated by the WRF channel model, followed by an evaluation of the simulated space-time spectral characteristics of rainfall. These evaluations set the stage for a detailed assessment of the simulated climatology and structures of tropical waves in Sects. 4 and 5.

\subsection{Time-mean spatial pattern}

Comparison of Fig. 1a and b shows that the WRF model is able to capture the general pattern of observed time-mean rainfall, including the relatively narrow strip of rain across the central north Pacific. Several notable smaller-scale features are also apparent, such as local rainfall enhancements near the Western Ghats of India and the highlands of Burma, both associated with the Asian summer monsoon (Xie et al. 2006). These monsoon features are much too strong, however, as illustrated by the difference map in Fig. 1c. More broadly, Fig. 1c reveals a systematic bias in the simulated rainfall, with generally too much rain at offequatorial latitudes (roughly $10^{\circ} \mathrm{N} / \mathrm{S}-20^{\circ} \mathrm{N} / \mathrm{S}$ ) and too little rain near the equator (roughly $10^{\circ} \mathrm{S}-10^{\circ} \mathrm{N}$ ). The positive off-equatorial bias can be seen almost everywhere, except the eastern Atlantic and Africa, with the largest enhancements occurring over the northwest and northeast Pacific. Meanwhile, the negative equatorial bias is most prominent near significant coastal regions, such as the west coasts of Sumatra, Columbia, and Cameroon and the east coast of Brazil.

Interestingly, a very similar type of bias pattern has been found in the superparameterized CAM (SP-CAM) mentioned previously (Khairoutdinov et al. 2008), as well as the superparameterized version of the NASA Goddard finite-volume general circulation model (fvGCM; Tao et al. 2009). Meanwhile, a positive off-equatorial rain bias has been seen in a number of recent high-resolution (but still not convection-resolving) simulations of the Asian summer monsoon (Cherchi and Navarra 2007; Lau and Ploshay 2009; Nguyen and McGregor 2009; Ratnam et al. 2009). Given that this type of bias does not appear as prominently in the conventional versions of the CAM and 
Fig. 1 Comparison of a simulated versus b TRMM annual mean rainfall during 2000-2005, along with $\mathbf{c}$ the difference between the two

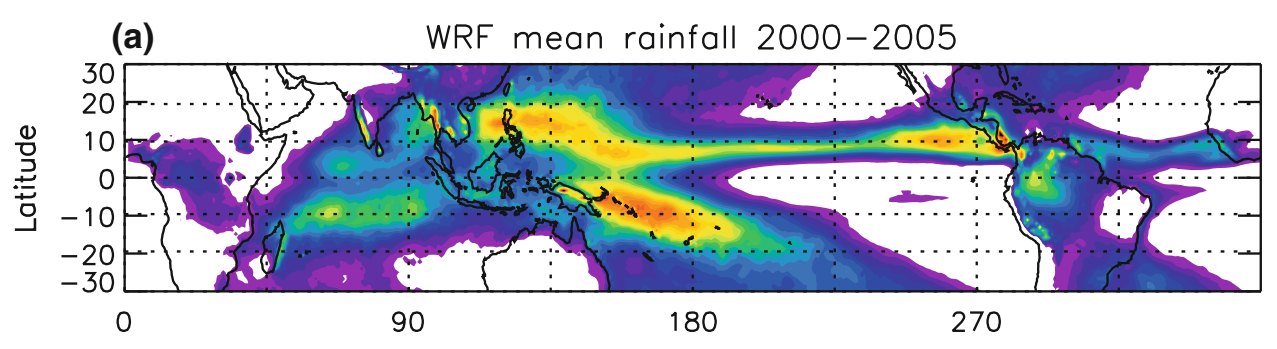

(b)

TRMM mean rainfall 2000-2005

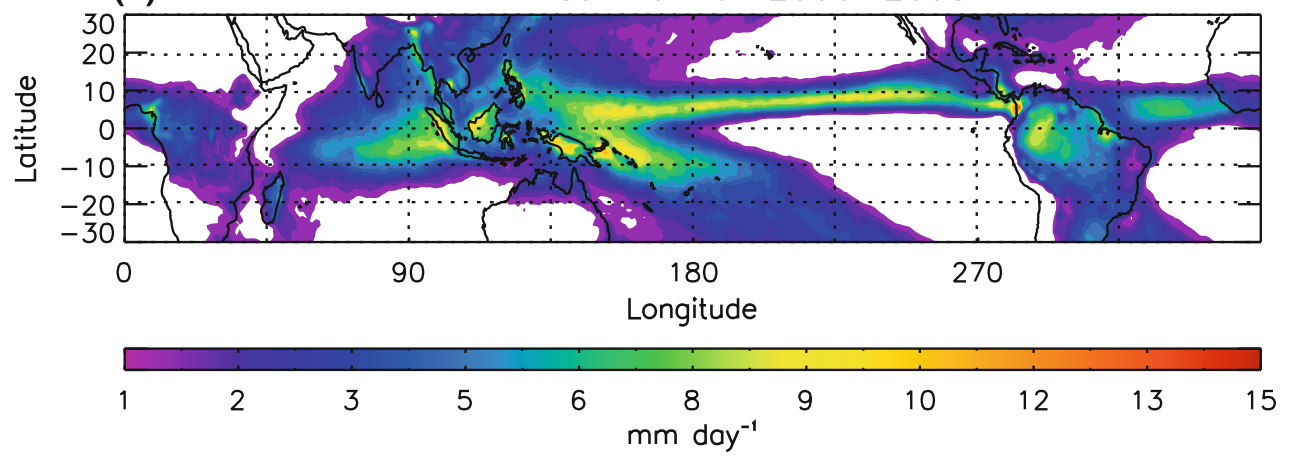

(c) WRF minus TRMM mean rainfall 2000-2005

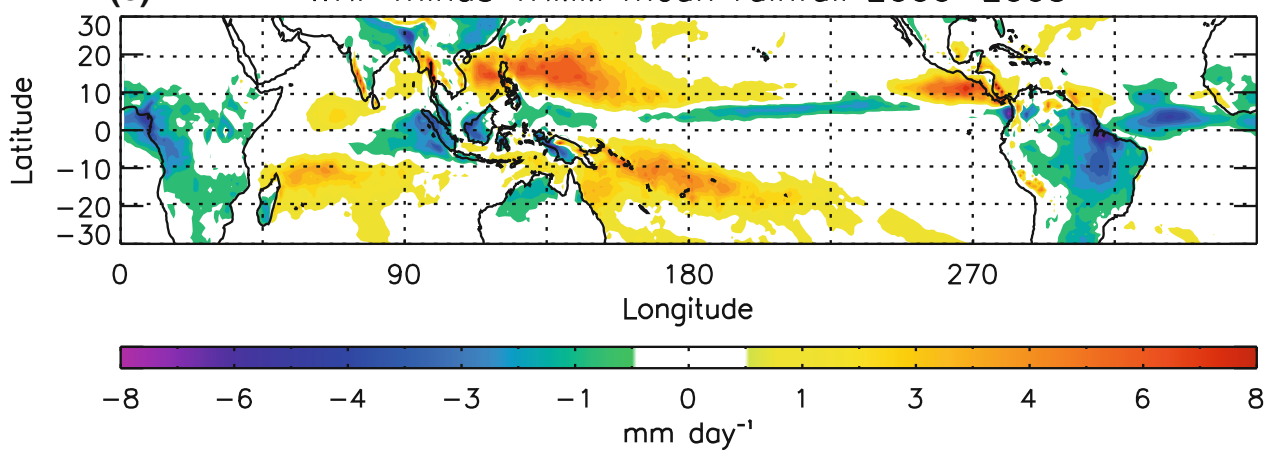

NASA fvGCM (Khairoutdinov et al. 2008; Tao et al. 2009), it would seem that the coupling between parameterized convection and the resolved circulation is somehow involved. Along these lines, Khairoutdinov et al. (2005) showed that the SP-CAM's excessive rainfall in the northwest Pacific could be mitigated by altering the domain configuration of the model's cloud-resolving convective parameterization. Alternatively, Ratnam et al. (2009) showed that the positive rainfall bias in their simulations of the Asian summer monsoon could be mitigated by allowing two-way coupling between the ocean and atmosphere. However, this improvement came at the expense of producing a compensating negative bias in the underlying SST (with amplitude of $\sim 1^{\circ} \mathrm{C}$ ). Thus the bias in precipitation was simply shifted to a different component of the coupled model system. Similar findings were obtained in the recent coupled-model studies of Cherchi and Navarra (2007) and Lau Ploshay (2009).

\subsection{Fourier spectral analysis}

The methodology of Wheeler et al. (2000) is used to isolate Kelvin and easterly waves in the model and observations (see also Straub and Kiladis 2002; Kiladis et al. 2006). Briefly, spectral filters are constructed based on space-time spectra of some form of proxy data for convective activity; the filters are tailored to capture the wavenumbers and frequencies of the wave modes of interest. Upon applying the filter and then transforming back to physical space, one obtains a filtered time series at each grid point. This method is appealing both for its simplicity and ease of implementation, but suffers from at least one drawback. Namely, the filtered time series includes a background "noise" component, as well as a component due to the waves. This noise component makes it difficult to quantitatively assess the spatial patterns of wave activity in the model (using the filtered variance as a proxy), since the 
simulated levels of background noise may be different than observed. However, qualitative evaluations are still possible.

Figure 2a shows that model's level of background noise is indeed different than observed, comparing the typical frequency power spectra of rainfall at a point. Both spectra show a sharp peak at the diurnal harmonic, but otherwise resemble red noise, i.e., power decays rapidly with increasing frequency. The rate of decay is more gradual in the observations, however, such that the simulated power is larger (smaller) than observed for periods smaller (larger) than roughly 6 days. When cast in physical space, this difference translates to the lagged autocorrelation of rain decaying more slowly in the model than observations. Figure $2 \mathrm{~b}$ shows that the time at which the autocorrelation decays to $1 / 2$ (a measure of the local time scales of convection) is larger in the model by roughly a factor of three. Similar findings were obtained by Ricciardulli and Sardeshmukh (2002) in their evaluation of convection variability in the NCAR Community Climate Model (CCM), a predecessor of the CAM. More recently, Lin et al. (2006) documented an overly red rainfall spectra in 13 out of 14 global coupled climate models participating in the Intergovernmental Panel on Climate ChangeÕs (IPCC) Fourth Assessment Report (AR4).

Extending our analysis to the spatial domain, Fig. 3 compares the typical zonal wavenumber-frequency spectra of the symmetric component of rainfall about the equator (computed as in Wheeler and Kiladis 1999). Both spectra show enhanced power along the dispersion curves of shallow-water Kelvin modes with equivalent depths $h \approx$ $20 \mathrm{~m}$. Enhanced power is also seen at negative wavenumbers (implying westward propagation) along the dashed curves extending from the origin. These dashed curves do not correspond to a "pure" theoretical wave mode, but rather denote the dispersion properties of the $n=1$ equatorial Rossby (ER) wave under doppler shifting by $7 \mathrm{~ms}^{-1}$ background easterlies. Studies by Kiladis et al.
(2006) and Serra et al. (2008) have shown that easterly wave fluctuations are mainly responsible for the enhancement in westward-moving power at synoptic wavenumbers and frequencies (loosely zonal wavelengths of 4,000 $6,000 \mathrm{~km}$ and periods of 3-7 days). Here we merely point out that the correspondence of this enhanced power to the doppler-shifted ER dispersion curve is consistent with the notion that easterly waves can be thought of as convectively coupled Rossby gyres advected by a mean easterly current (e.g., Shapiro 1978; Sobel and Bretherton 1999; Magnusdottir and Wang 2008).

While the simulated and observed spectra in Fig. 3 appear broadly similar, there are at least two notable differences. First, the Kelvin wave signals in Fig. 3a are not as prominent as in Fig. 3b, suggesting that the simulated Kelvin waves are generally less active than observed. Secondly, the most prominent spectral speak in Fig. 3b, appearing at wavenumbers $k=1-4$ and periods in the range 40-50 days, is absent from Fig. 3a, suggesting that the model is not producing an $\mathrm{MJO}$, at least in terms of rainfall. Given that the model spectrum in Fig. 3a looks otherwise realistic, this failure of the model indicates that the dynamics of the MJO involves more than just coupling between convection and planetary-scale Kelvin waves (see also Lin et al. 2006).

Significant differences are also seen when comparing the simulated versus observed spectra of the antisymmetric component of rainfall, depicted in Fig. 4. Specifically, the spectral signals of both the $n=0$ mixed Rossby-gravity (MRG) and eastward-moving inertiagravity waves are largely absent from Fig. 4a, suggesting that the model is not producing either of these disturbances, in addition to rainfall signals associated with MJO. Interestingly, the SP-CAM is found to have a similar problem, even though it produces a relatively robust MJO in terms of rainfall (M. Khairoutdinov 2008, personal communication). The reasons for these model deficiencies are not yet clear.
Fig. 2 Typical a frequency power spectra and $\mathbf{b}$ temporal autocorrelation of tropical rainfall in the model (solid) and TRMM data (dotted). Frequency spectra were obtained as the averaged spectra for successive (partly overlapping) 96-day segments during 2000-2005 for all grid points between $15^{\circ} \mathrm{S}$ and $15^{\circ} \mathrm{N}$. The autocorrelation was obtained as the inverse Fourier transform of the averaged frequency spectra (a) Rain power spectra

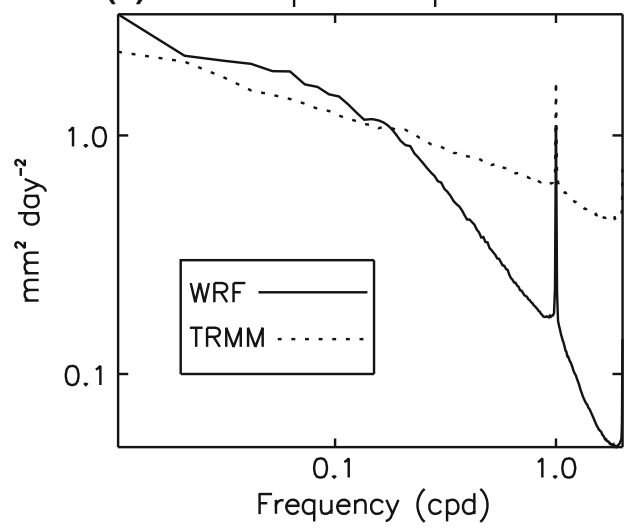

(b) Rain autocorrelation

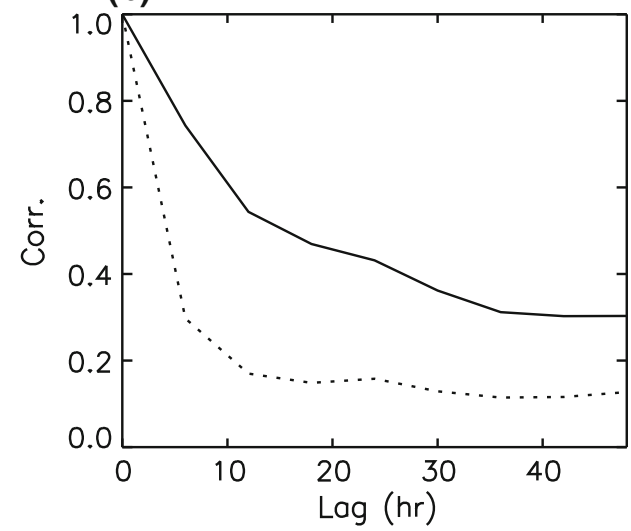


(a) $\log _{10}\left[\mathrm{WRF} P_{S}\right] 14.5 \mathrm{~S}-14.5 \mathrm{~N}$

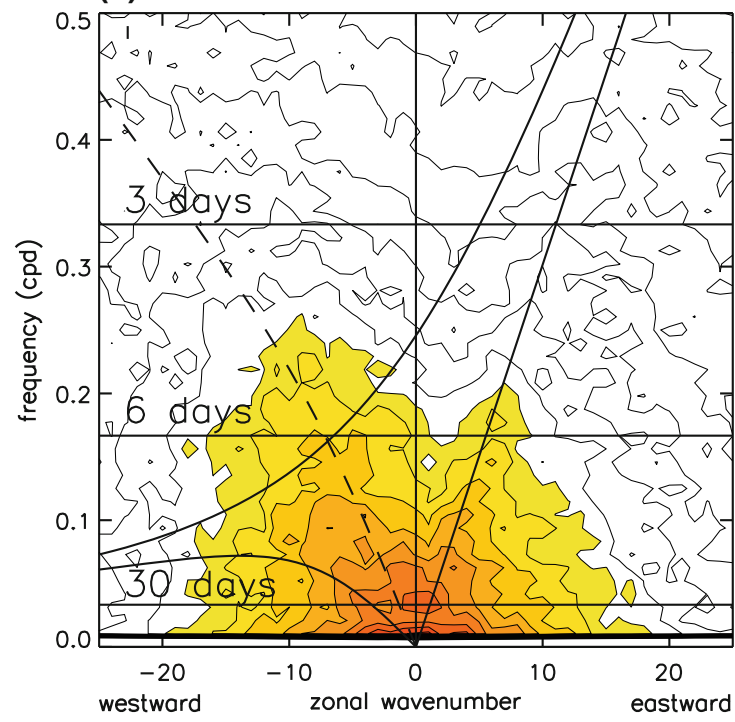

Fig. 3 Typical wavenumber-frequency power spectra of the symmetric component of rainfall about the equator (cf. Wheeler and Kiladis 1999) in the a model and b TRMM satellite data. Solid curves denote theoretical dispersion curves of shallow-water Kelvin, $n=1$ equatorial Rossby (ER), and mixed-Rossby gravity modes with

(a) $\quad \log _{10}\left[\right.$ WRF $\left.P_{A}\right] 14.5 \mathrm{~S}-14.5 \mathrm{~N}$

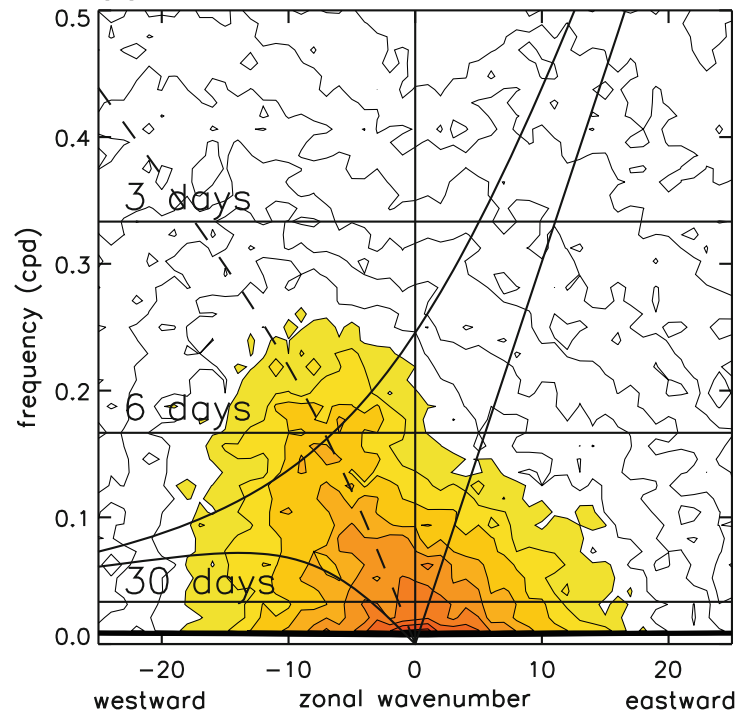

(b) $\log _{10}\left[\right.$ TRMM $\left.P_{S}\right] 14.5 \mathrm{~S}-14.5 \mathrm{~N}$

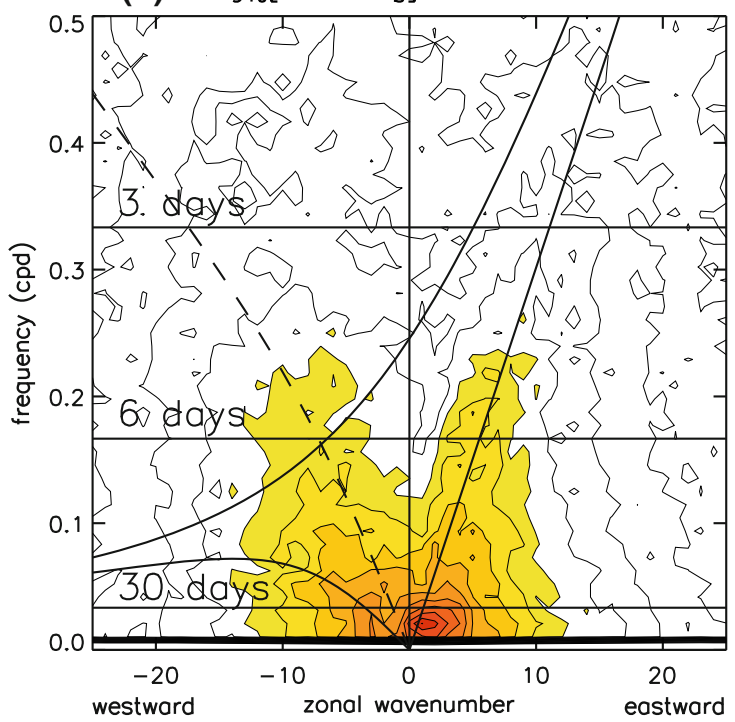

equivalent depth $h=20 \mathrm{~m}$. Dashed curve denotes the $n=1$ ER dispersion curve under doppler shifting by $7 \mathrm{~m} \mathrm{~s}^{-1}$ background easterlies. Base-10 logarithm is taken for plotting with contour intervals of $1.25 \times 10^{-1}$ and shading at -1.8 and above (original units are $\mathrm{mm}^{2} \mathrm{day}^{-2}$ )

(b) $\quad \log _{10}\left[\mathrm{TRMM} P_{A}\right] 14.5 \mathrm{~S}-14.5 \mathrm{~N}$

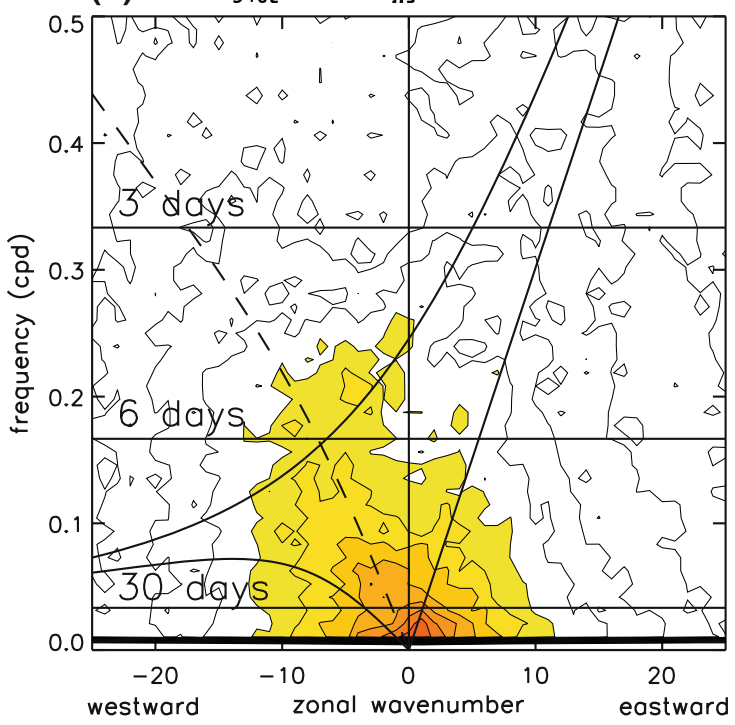

Fig. 4 Similar to Fig. 3, but for the antisymmetric component of rainfall

To quantify the differences between the model and observations, we introduce the quantities $P_{\mathrm{E}}$ and $P_{\mathrm{W}}$, which respectively denote the eastward- and westward-propagating components of rainfall variance (including symmetric and antisymmetric components) summed over wavenumbers $k=1-25$. Inspection of Fig. 5 shows that the ratio of $P_{\mathrm{W}}$ to $P_{\mathrm{E}}$ is larger in the model than observations for periods greater than roughly 12 days. The largest differences are seen at periods in the range 4-7 days, which can be attributed to the model's under prediction of Kelvin wave activity, and overprediction of easterly wave activity. A similar type of result was obtained by Yang et al. (2009) in their analysis of convection variability in two Hadley centre atmospheric general circulation models (see their Fig. 3). As with their study, we find that the bias towards westward-moving variance cannot be explained by biases in the background flow (i.e., mean easterlies being stronger than observed; results not shown). 


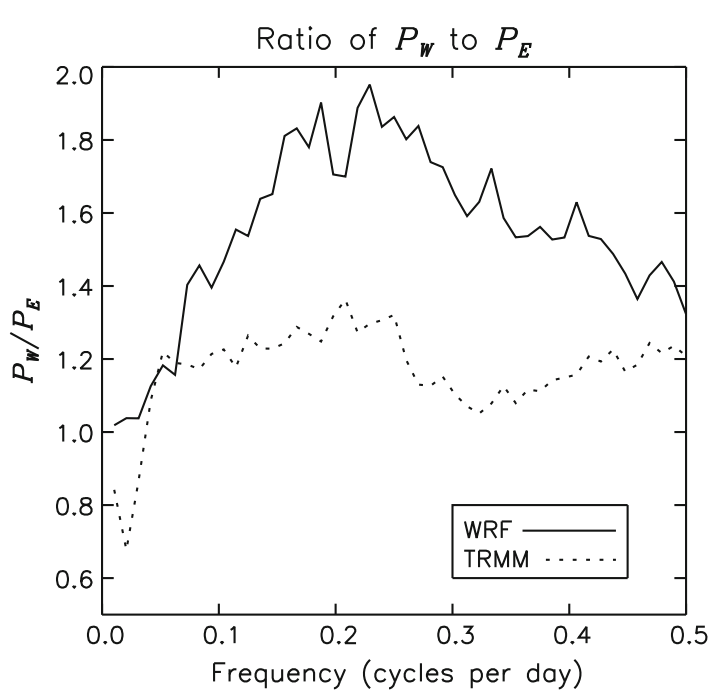

Fig. 5 Ratio of westward- to eastward-moving rainfall variance summed over wavenumbers $k=1-25$ for the model (solid) and TRMM data (dotted). See text for details

\subsection{Definition of spectral filters}

Spectral filters were used to isolate Kelvin and easterly waves in the model and observations. To illustrate how the filters were chosen, Fig. 6 shows the simulated versus observed spectra of the symmetric component of rainfall during June through August. Both spectra have been normalized by their respective (smoothed) background spectra, following Wheeler and Kiladis (1999). Spectral enhancements associated with Kelvin and easterly waves

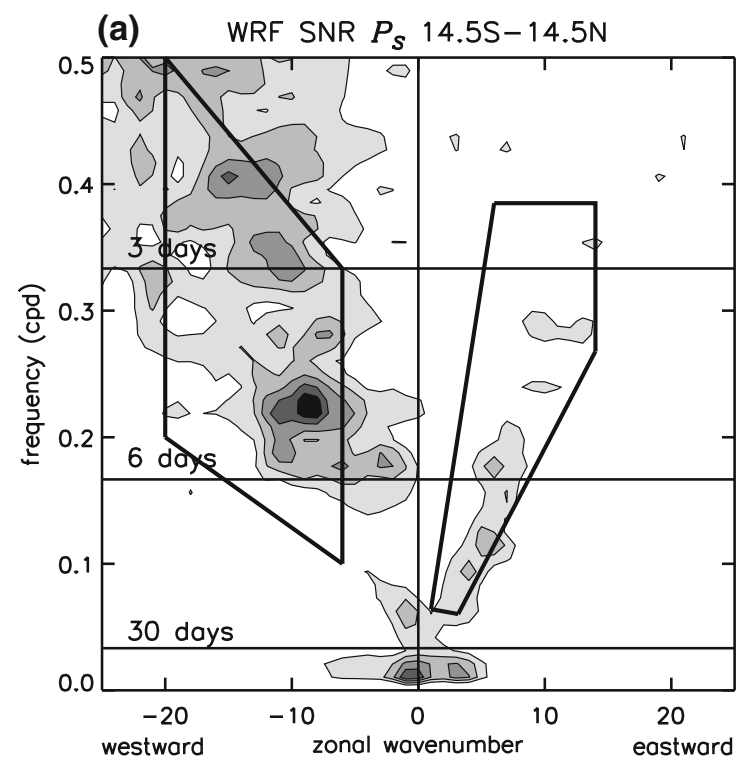

Fig. 6 Typical wavenumber-frequency spectra of the symmetric component of June-August rainfall (normalized by a smoothed background spectra following Wheeler and Kiladis 1999) for the a model and b TRMM data. Shading starts at a value of 1.05 , with are evident in both diagrams. However, the Kelvin (easterly) wave peak is smaller (larger) in the model spectrum, consistent with differences seen earlier in the raw spectra. The locations of the peaks are also different, implying slight differences in the dominant scales and phase speeds of the waves. For example, Kelvin waves in the model have slightly slower implied phase speeds than observed. The heavy solid lines, which denote the boundaries of the spectral filters, enclose the spectral peaks of both wave types. The shapes of the filters are broadly similar to those used in Straub and Kiladis (2002) and Kiladis et al. (2006).

\section{Kelvin wave assessment}

Results in the previous section showed that Kelvin and easterly waves are both present in the WRF channel model, although their overall levels of activity are different than observed. In this section, we examine more closely the simulated Kelvin waves, including their spatial climatology, structures, and evolution. A similar evaluation of the simulated easterly waves is given thereafter in Sect. 5 .

\subsection{Spatial climatology}

Maps of Kelvin-wave-filtered rain variance (including both the symmetric and anti-symmetric components of rainfall) are used to assess the spatial pattern of Kelvin wave activity in the model. The variance pattern in the model,

(b) TRMM SNR $P_{S} 14.5 \mathrm{~S}-14.5 \mathrm{~N}$

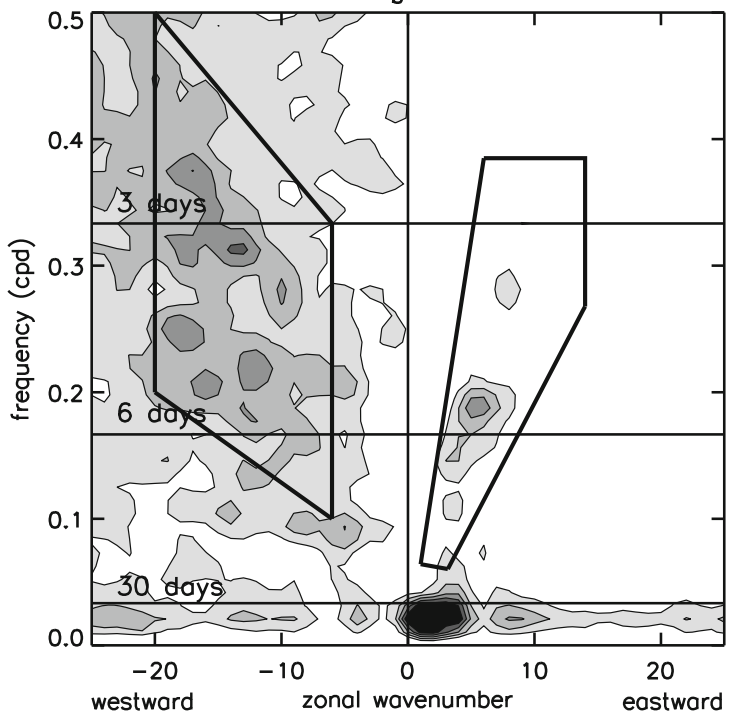

contour intevals of 0.2. Heavy solid lines denote the filters used to isolate Kelvin and easterly waves. The spectra have been lightly smoothed for viewing purposes 
depicted in Fig. 7a, shows three main centers of action in the western Pacific at latitudes of roughly $15^{\circ} \mathrm{S}, 5^{\circ} \mathrm{N}$, and $17^{\circ} \mathrm{N}$. The two at higher latitudes are not really associated with Kelvin waves per se, but rather reflect enhancements in random convective variability associated with the model's off-equatorial rain bias (see Fig. 1c).

In addition to north-south biases in variance, east-west biases can also be seen. Figure $7 \mathrm{a}$ indicates that Kelvin waves in the model are confined mainly to the Indo-Pacific region, whereas Fig. $7 b$ suggests Kelvin waves in nature can be found throughout the tropics, including over South America and Africa (see also the observations by Liebmann et al. 2009 and Mekonnen et al. 2008). Presumably, the dearth of Kelvin wave activity over South America and Africa stems from the same mechanistic process responsible for corresponding deficits in time-mean rainfall and convection (e.g., compensating subsidence and convective stabilization due to enhanced time-mean rainfall elsewhere; cf. Fig. 1c).

\subsection{Composite evolution of rainfall}

The method of lagged-linear regression is used to characterize the typical structures and evolution of Kelvin waves in the model and observations (e.g., Straub and Kiladis 2003). Briefly, time series of raw data are regressed onto a time series of filtered data (in this case, Kelvin-wave-filtered rainfall) at a selected base point. For convenience, the filtered time series is normalized to have a standard deviation of unity, so that regression coefficients have the same units as the raw data and convey the typical amplitude of wave anomalies. The base point for the model analysis is chosen as the location where the simulated Kelvin wave activity is largest $\left(165^{\circ} \mathrm{E}, 4.5^{\circ} \mathrm{N}\right.$; see Fig. $\left.7 \mathrm{a}\right)$. Meanwhile, the base point for the observational analysis is chosen as the tropical island of Majuro $\left(171^{\circ} \mathrm{E}, 7.5^{\circ} \mathrm{N}\right)$, where twice-daily soundings are recorded and observed Kelvin waves are relatively active (see Fig. 7b).

Regressions of raw rainfall data onto Kelvin-wave-filtered rain data, depicted in Fig. 8, convey the typical phase speed and evolution of Kelvin waves over the Pacific. The phase speed of the simulated waves is estimated to be somewhat slower than observed ( 13 vs. $15 \mathrm{~ms}^{-1}$ ), consistent with the differences in spectral signals seen earlier in Fig. 6. The implied genesis and termination locations of the waves are also different: comparison of Fig. 8a and b suggests that the simulated waves generally form over the Indian Ocean and terminate over the central Pacific, whereas the observed waves form and decay many thousands of kilometers to the east, traveling all the way to the western coast of Central America. The more rapid termination of the simulated waves is consistent with the eastwest biases in Kelvin wave activity mentioned earlier.

\subsection{Vertical dynamical structures}

In spite of these differences, the vertical dynamical structures of the simulated and observed waves are found to be
Fig. 7 Maps of Kelvin-wavefiltered rain variance (including both symmetric and antisymmetric components) for the a model and b TRMM satellite data. Asterisks denote the base points for statistical analyses in Figs. 8, 9, 10

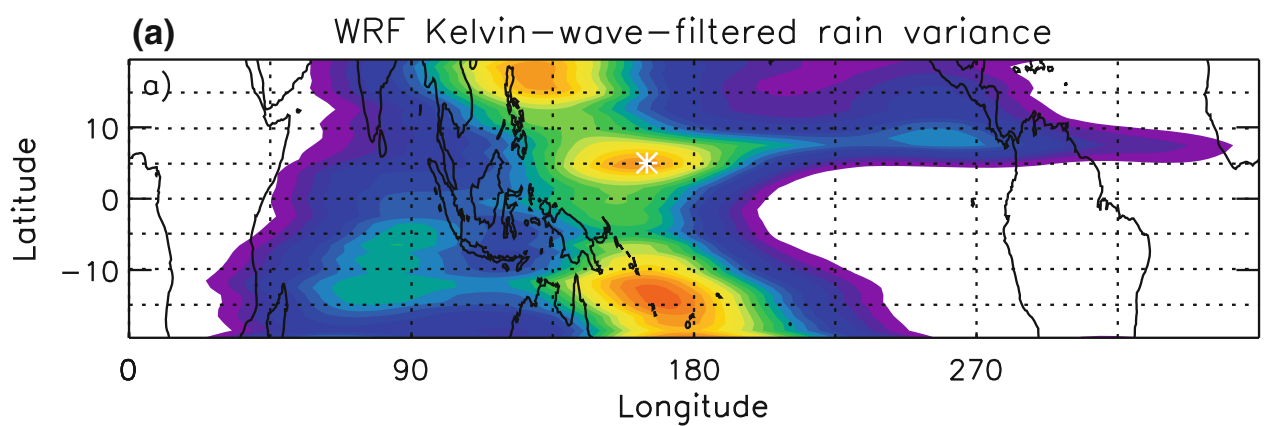

(b) TRMM Kelvin-wave-filtered rain variance

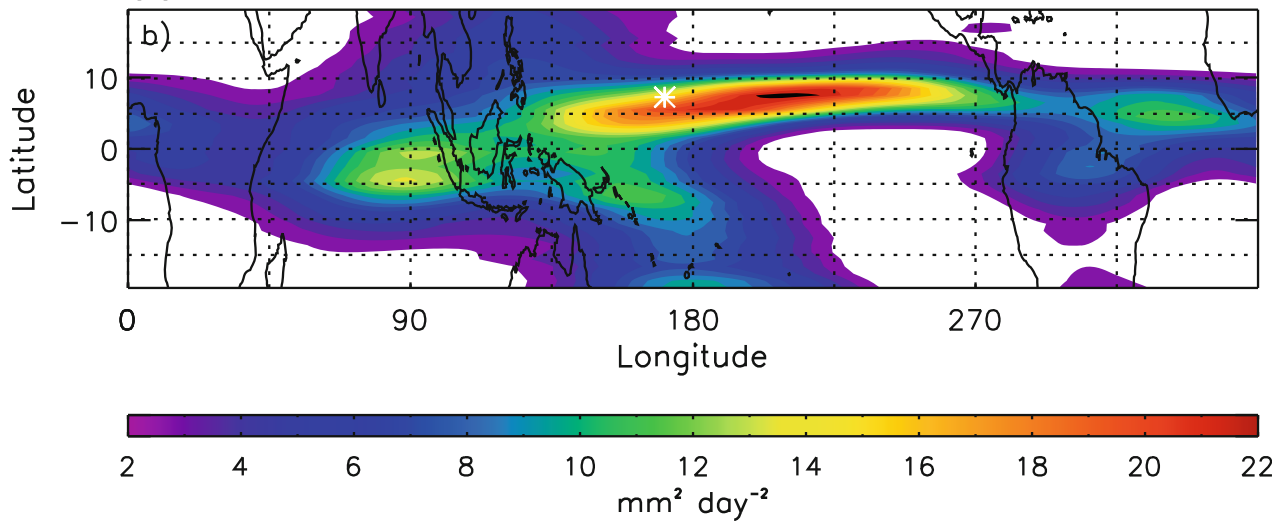




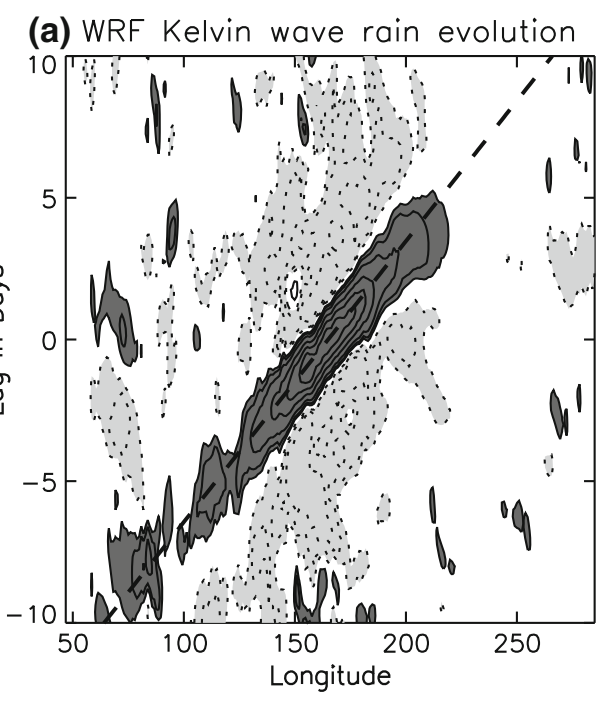

Fig. 8 Regressed space-time evolution of rainfall associated with convectively coupled Kelvin waves in the a model and b TRMM satellite data. Results are based on lagged linear regressions of raw rainfall data onto Kelvin-wave-filtered data at base point in the central Pacific (see Fig. 7). Heavy (light) shading denotes positive (negative)

broadly similar. The upper three left panels of Fig. 9 depict the typical time-height evolution of temperature, specific humidity, and zonal wind anomalies associated with convectively coupled Kelvin waves in the model, as computed using lagged linear regression. The tilted anomaly patterns are qualitatively similar to those obtained using twice-daily sounding data at Majuro, depicted in the upper three right panels of Fig. 9 (see also Straub and Kiladis 2003). The simulated tilts are notably too smooth, however, suggesting that convection in the model develops too gradually as the Kelvin wave approaches from the east (i.e., the rapid upward growth of moisture during the 12-24 h prior to peak rainfall is not apparent in Fig. 9c). Similar evidence for a rapid growth of convection in large-scale tropical waves (as well as individual mesoscale convective systems) can be found in the independent observational/model analyses of Mapes et al. (2006). Presumably, the pronounced suppression of observed rainfall and convection at negative lags in the range -60 to $-24 \mathrm{~h}$ is due in part to strong dryness in the lower to middle troposphere (cf. Derbyshire et al. 2004), which is not captured by the model (see Figs. 9c, d).

Another deficiency of the model is the generally larger amplitude of low-level temperature versus moisture anomalies. For example, the ratio of $850-\mathrm{hPa}$ moisture to temperature anomalies at lag 0 is roughly three times larger in the model than observed. While this deficiency could stem from parameterized convection in the model being overly sensitive to temperature as compared to moisture, it could also simply reflect errors in the parameterized convective heating and drying rates, so interpretation is not clear. Either way, the qualitative similarities between the
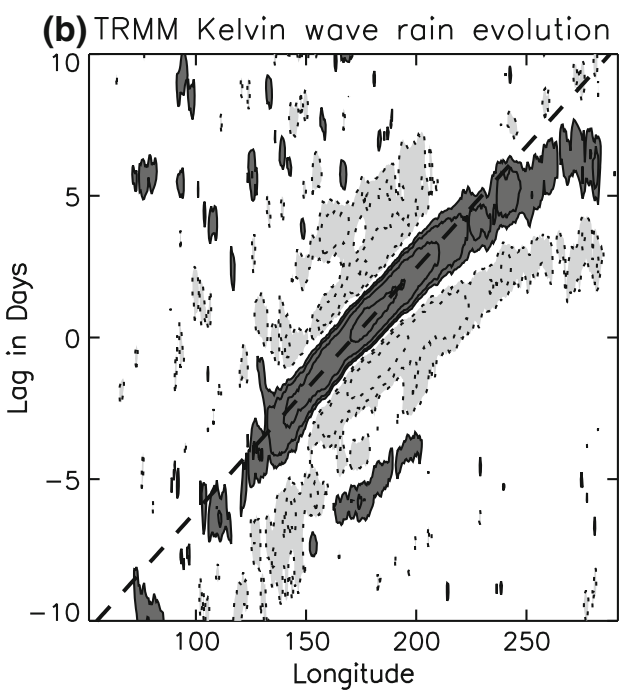

regression coefficients with magnitude greater than $0.25 \mathrm{~mm} \mathrm{day}^{-1}$. Contours denote absolute values of $0.25,0.5,1,2,3$, and $4 \mathrm{~mm} \mathrm{day}^{-1}$. Regression coefficients have been averaged over a meridional band of width $5^{\circ}$, centered on the base point. Dashed lines denote phase speeds of either a 13 or $\mathbf{b} 15 \mathrm{~ms}^{-1}$

simulated and observed vertical wave structures suggests that the model is capturing the basic dynamics of the phenomenon.

\subsection{Horizontal dynamical structures}

Qualitative similarities are also seen when comparing the simulated versus observed horizontal wave structures. For example, the 700-hPa temperature and horizontal wind anomaly patterns in Fig. 10a and b show features resembling theoretical Kelvin waves, i.e., winds are predominantly in the east-west direction and temperature perturbations are generally largest at the equator. The quantitative differences between the simulated and observed wave patterns, e.g., cold temperature anomalies and easterly winds are more pronounced to the west of enhanced rainfall in the model, are broadly consistent with those expected on the basis of Fig. 9.

The overall success of the model in capturing the observed structures and phase speeds of convectively coupled Kelvin waves stands in contrast to many contemporary low-resolution global climate models. For example, Straub et al. (2009) recently found that only 5 out of 20 IPCC-AR4 models produce moist Kelvin waves resembling observations.

\section{Easterly wave assessment}

The previous section showed that the structures and phase speeds of convectively coupled Kelvin waves are 
(a) WRF $T$ anom. (165E, 7.5N)

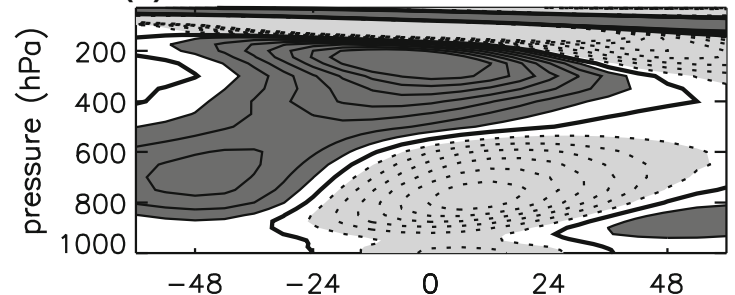

(c)

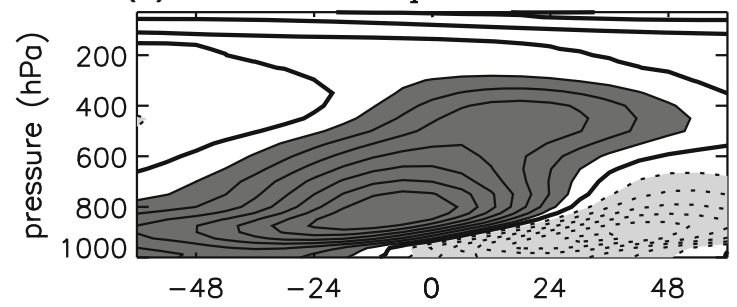

(e) WRF $u$-wind anom.

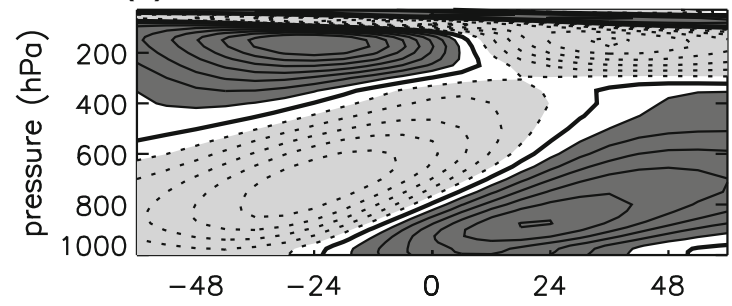

(g) WRF rainfall anom.

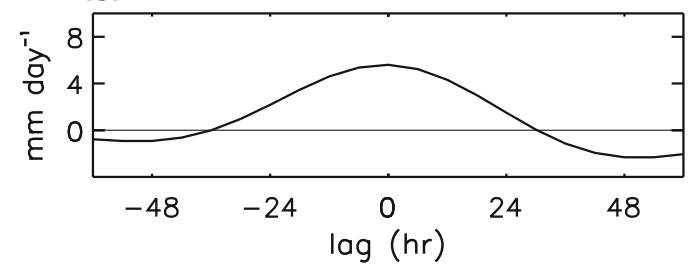

Fig. 9 Regressed time-height evolution of temperature (a, b), specific humidity $(\mathbf{c}, \mathbf{d})$, and zonal wind $(\mathbf{e}, \mathbf{f})$ anomalies associated with convectively coupled Kelvin waves in the model (left) and observations (right), together with the corresponding evolution of rainfall anomalies $(\mathbf{g}, \mathbf{h})$. Observational results are based on twice-

reasonably well captured by the WRF channel model, although their spatial climatology is not. In this section, we describe a similar evaluation of the model's easterly waves, and also assess the statistical relationship between the simulated waves and TC genesis.

\subsection{Spatial climatology}

Figure 11 shows that the simulated easterly wave variance is relatively too high over the Indian and Pacific basins, and too low over South America, Africa, and the Atlantic. As with the missing Kelvin waves in the model, we speculate that the missing easterly waves over Africa and the Atlantic

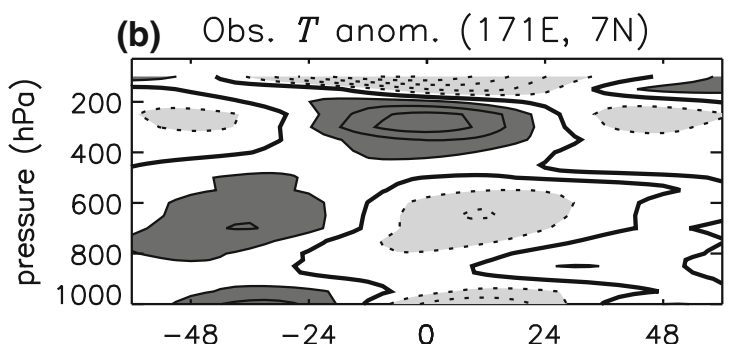

(d)

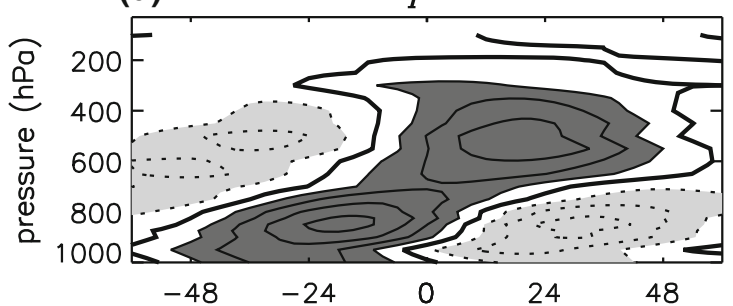

(f) Obs. $u$-wind anom.

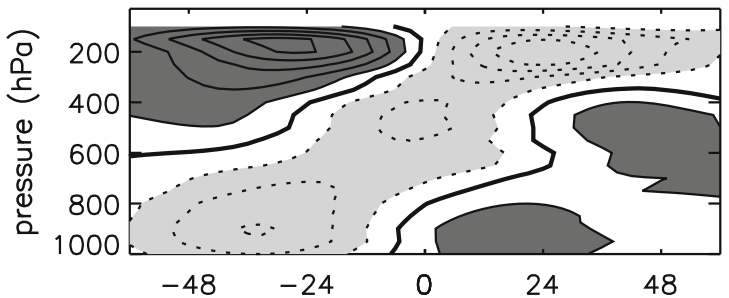

(h) TRMM rainfall anom.

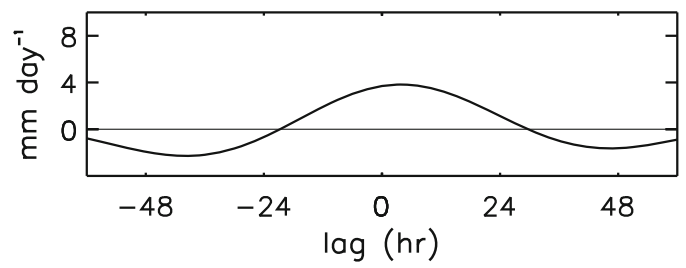

daily sounding data at Majuro. Solid (dotted) contours with dark (light) shading denote positive (negative) anomalies. Contour increments for temperature, moisture, and winds are $5 \times 10^{-2} \mathrm{~K}, 4 \times$ $10^{-2} \mathrm{~g} \mathrm{~kg}^{-1}$, and $2 \times 10^{-1} \mathrm{~ms}^{-1}$, respectively. The zero contour is heavy

stem from the same model deficiencies responsible for suppressing time-mean rainfall and convection. Focusing on the Indian and Pacific sectors, we see that the model captures the two relatively weak maxima in wave activity in the Southern Hemisphere (located east and west of Indonesia), as well as the much stronger maximum in the Northern Hemisphere, located just east of the Philippines. However, all three maxima are positioned several or more degrees poleward of their observed counterparts, similar to the meridional biases in time-mean rainfall noted earlier in Fig. 1c. The simulated variance is also much too large in the far west Pacific as compared to further east. A possible explanation for these differences can be found below. 
(a) WRF 700-hPa temp. and winds at lag 0

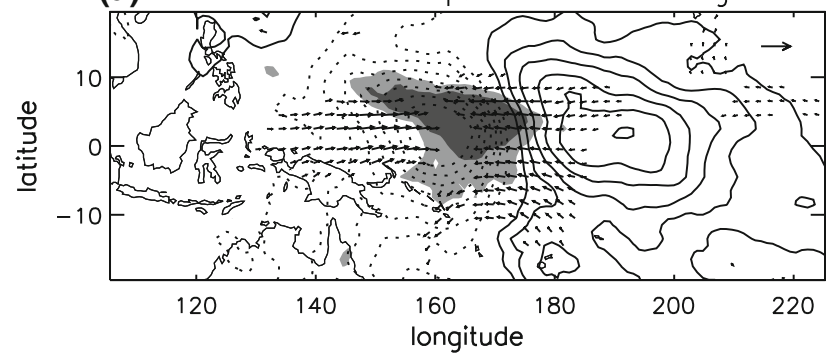

(b) JRA25 700-hPA temp. and winds at lag 0

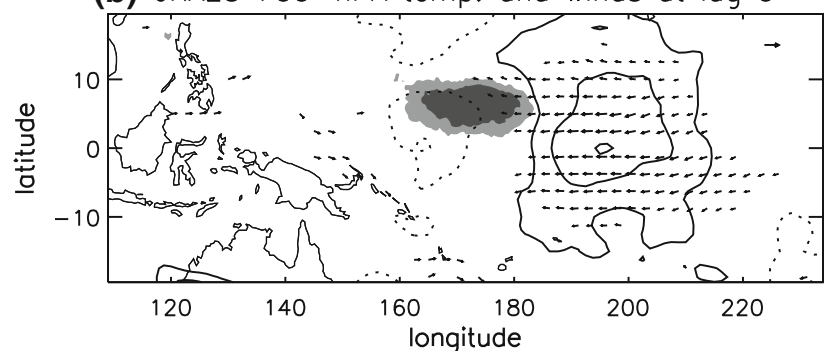

Fig. 10 Horizontal dynamical structures of convectively coupled Kelvin waves in the a model and $\mathbf{b}$ Japanese Reanalysis data. Results are based on lag-0 linear regressions of temperature (contours) and horizontal winds (vectors) onto Kelvin-wave-filtered time series of rainfall at a base point in the Pacific (see Fig. 7). Solid (dotted) contours denote positive (negative) temperatures with increments of 3 $\times 10^{-2}$. Only wind vectors that are statistically significant at the $95 \%$ confidence level are shown. Light (dark) shading denotes raw rainfall regression coefficients in excess of 1 (2) $\mathrm{mm} \mathrm{day}^{-1}$. Wind vectors at upper right denote wind speeds of a 2 and $\mathbf{b} 0.5 \mathrm{~ms}^{-1}$, respectively

\subsection{Composite evolution of rainfall}

Figure 12 compares the space-time evolution of easterly waves in the model and observations, showing regressions of raw rainfall data onto easterly-wave-filtered data at the base point $171^{\circ} \mathrm{E}, 7.5^{\circ} \mathrm{N}$ (i.e., well upstream of the simulated/observed variance maximum in the west Pacific). The implied horizontal propagation speed $\left(\sim 9 \mathrm{~ms}^{-1}\right)$ and genesis/termination locations of the simulated waves appear broadly similar to those seen in the TRMM data. Unlike the latter, however, the simulated waves actually reach their largest amplitudes slightly to the west of the base point at a lag of +1 day; the simulated waves also generally feature larger amplitudes at lags beyond \pm 2 days. The implication is that easterly waves in the model are systematically amplifying as they move westward across the basin into the west Pacific, consistent with the time-mean rainfall bias in Fig. 1c.

\subsection{Vertical dynamical structures}

Differences are also seen when comparing the vertical structures of the simulated waves at $171^{\circ} \mathrm{E}, 7.5^{\circ} \mathrm{N}$ to observed structures based on Majuro sounding data. In particular, Fig. 13 shows that the model fails to capture the observed tilts in temperature and meridional winds in the middle to upper troposphere $(\sim 700-400 \mathrm{hPa})$; instead,
Fig. 11 Similar to Fig. 7, but for easterly-wave-filtered rain variance. Asterisks denote the base points for statistical analyses in Figs. 12, 13, 14 and 15

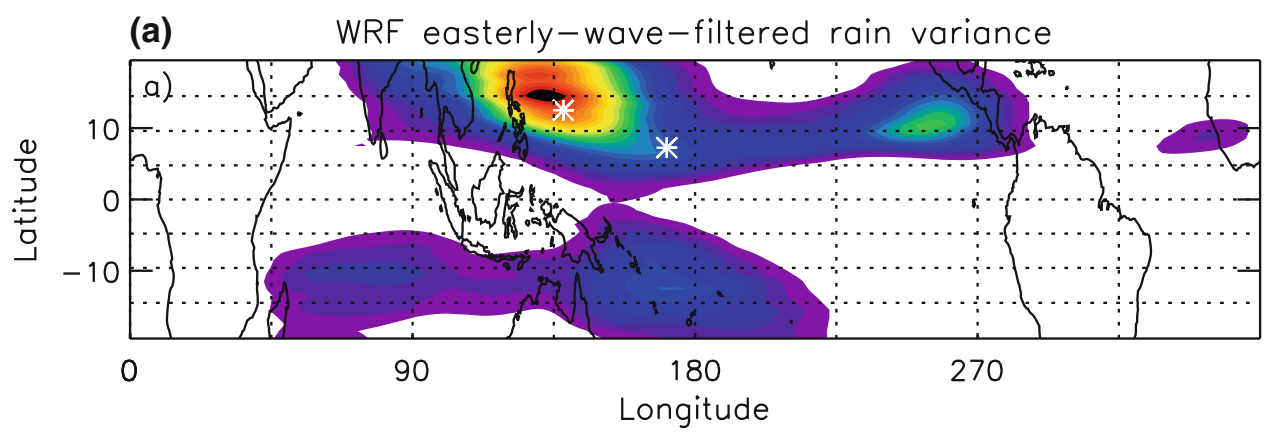

(b) TRMM easterly-wave-filtered rain variance

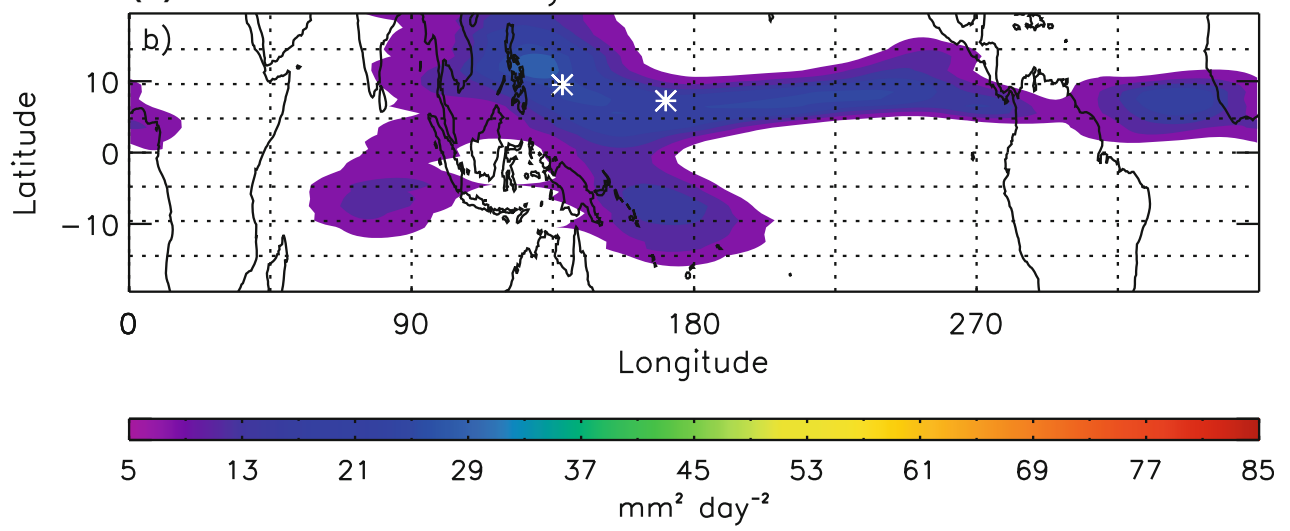


Fig. 12 Similar to Fig. 8, but for the regressed space-time evolution of rainfall associated with easterly waves at the base point $171^{\circ} \mathrm{E}, 7.5^{\circ} \mathrm{N}$ (see

Fig. 11). Dashed lines denote a westward propagation speed of $9 \mathrm{~ms}^{-1}$

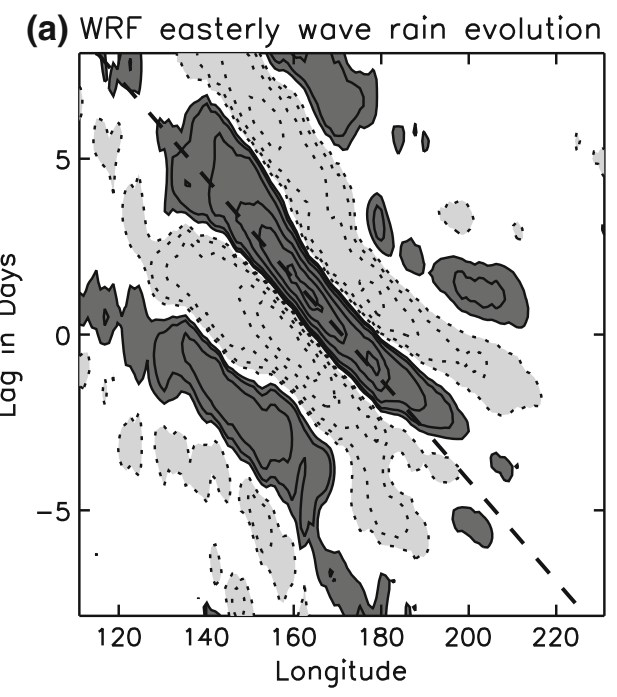

(b) TRMM easterly wave rain evolution

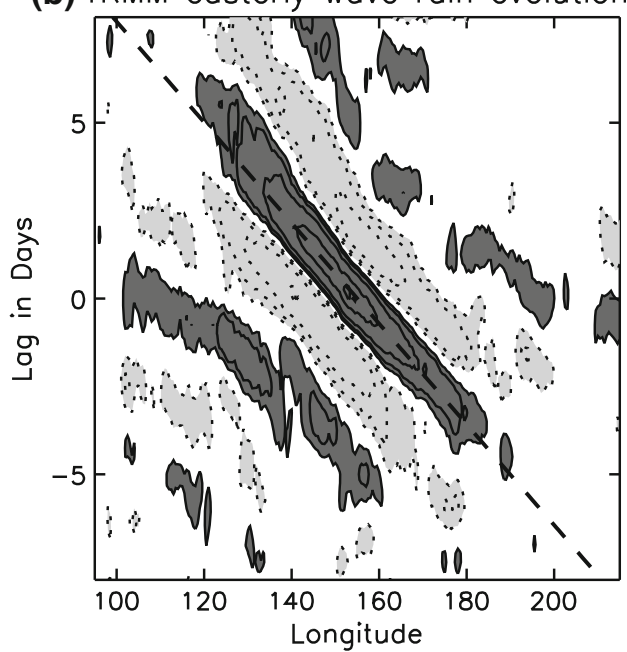

the anomalies are more or less vertically aligned and their amplitudes are generally much larger than observed. The model also fails to capture the surface-based temperature signals associated with convectively generated cold pools, which may stem from moisture (and temperature) anomalies in the simulated waves being shifted toward lower levels than observed (compare Fig. 13c, d). On a more positive note, both the model and observations show a buildup of convection in association with cooling and moistening of the lower free troposphere. This similarity suggests that low-level destabilization processes are indeed important for convection modulation, as postulated by Mapes (2000), Khouider and Majda (2006), Fuchs and Raymond (2007), Kuang (2008).

Looking at a base point further west, Fig. 14 shows that the model is able to capture several key observed changes in the vertical structures of the waves, as they move into (or develop in situ over) the west Pacific. These changes include: (1) a transition from rainfall peaking under lowlevel southerly flow to a near quadrature relationship between rainfall and low-level meridional winds; (2) the loss of vertical tilts in moisture; and (3) the development of "reverse" tilts in temperature (i.e., tilts with orientation opposite to that of the Kelvin waves; see also Reed and Recker 1971; Serra et al. 2008). These structural changes may be due in part to zonal variations in the vertical shear of the background zonal winds (cf. Holton 1971).

\subsection{Horizontal dynamical structures}

Zonal variations in the low-level (700-hPa) horizontal structures of the waves are also captured by the model, at least in a qualitative sense. Figure 15a shows that as the simulated waves travel across the central Pacific they appear as an east-west-oriented series of Rossby gyres, with predominantly isotropic (as opposed to tilted) flow anomalies in the vicinity of the base point at $171^{\circ} \mathrm{E}, 7.5^{\circ} \mathrm{N}$. Meanwhile, waves further west (at $138^{\circ} \mathrm{E}, 12.5^{\circ} \mathrm{N}$ ) have gyres that are generally tilted southwest to northeast and whose centers are oriented southeast to northwest (see Fig. 15c). Broadly similar variations are apparent in the reanalysis data depicted in Fig. $15 \mathrm{~b}$ and $\mathrm{d}$ (see also the observations of Lau and lau 1990; Serra et al. 2008). However, close inspection of Fig. 15c and d shows that the northwest-southeast orientation of the simulated wave train over the western north Pacific is somewhat less pronounced than in the reanalysis data, i.e., the center of the anticyclonic gyre to the east of the base point in the model is shifted poleward of the corresponding gyre in the reanalysis data. The amplitudes of the simulated waves are also much larger than observed, especially over the western Pacific.

\subsection{Easterly waves and TC genesis}

Observations show a strong linkage between easterly waves and TC genesis, with the former often serving as precursors for the latter (e.g., Landsea 1993; Chen et al. 2008; Frank and Roundy 2006). Hence it seems reasonable to expect that deficiencies in the model's easterly wave climatology lead to deficiencies in its climatology of TC genesis. Preliminary evidence to support this idea can be found in Fig. 16, which compares the statistics of TC genesis in the model versus observed "best-track" data. The statistics are shown for the three ocean basins where easterly waves are known to spawn TCs: the western and eastern north Pacific and the north Atlantic. TC tracking in the model was performed using an objective algorithm similar to that of Walsh et al. (2004). The model is seen to produce far too many storms over the western Pacific, and too few over the tropical Atlantic (between $0^{\circ}$ and $15^{\circ} \mathrm{N}$ ). A slight positive bias in genesis frequency is also seen over 


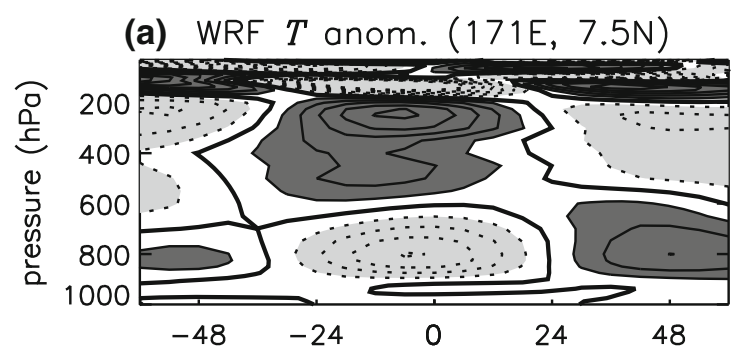

(c)

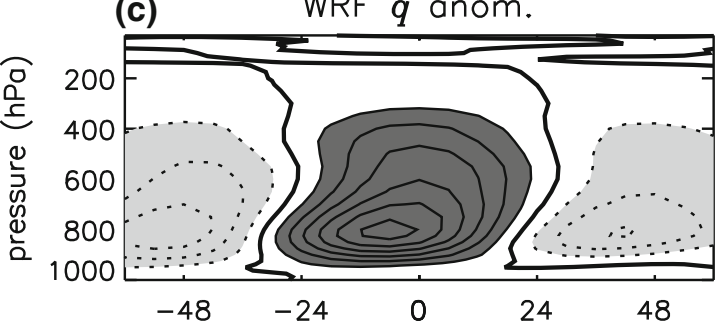

(e) WRF $v$-wind anom.

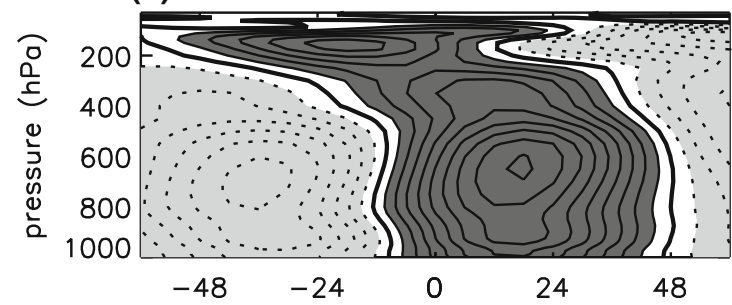

(g) WRF Rainfall anom.

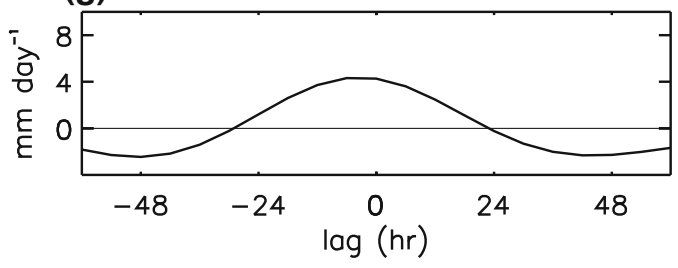

Fig. 13 Similar to Fig. 9, but for the regressed time-height evolution of temperature $(\mathbf{a}, \mathbf{b})$, specific humidity $(\mathbf{c}, \mathbf{d})$, and meridional wind $(\mathbf{e}, \mathbf{f})$ anomalies associated with easterly waves at the base point $171^{\circ} \mathrm{E}, 7.5^{\circ} \mathrm{N}$, together with the corresponding rainfall evolution

the tropical eastern Pacific. These biases are highly correlated with the biases in easterly wave activity seen earlier in Fig. 11.

A novel threshold technique was used here to objectively estimate the number of TCs which develop from easterly waves in the model versus observations. To illustrate, Fig. 17 shows histograms of coarse-grained $\left(5^{\circ} \times 5^{\circ}\right)$ easterly-wave-filtered rainfall $\left(P_{\text {ew }}\right)$ calculated for the genesis locations (and times) of the set of simulated/ observed TCs that developed between $0^{\circ}$ and $15^{\circ} \mathrm{N}$ in either the Pacific or Atlantic. Both distributions exhibit positive skewness, as well a positive mean, indicating that TCs typically form when easterly wave rainfall is locally enhanced. The dashed lines in Fig. 17 denote the standard (b) Obs. $T$ anom. (171E, 7N)

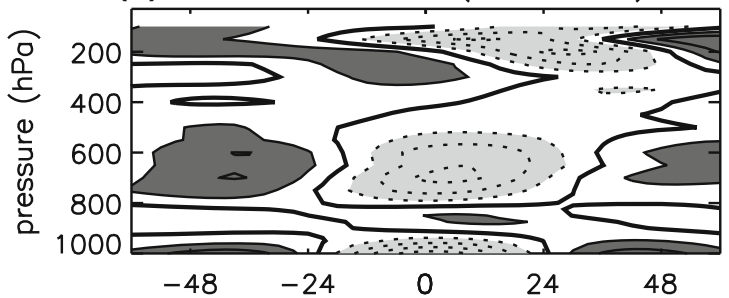

(d) Obs. $q$ anom.

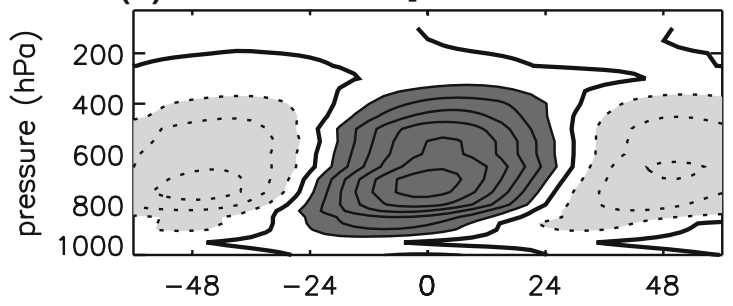

(f) Obs. $v$-wind anom.

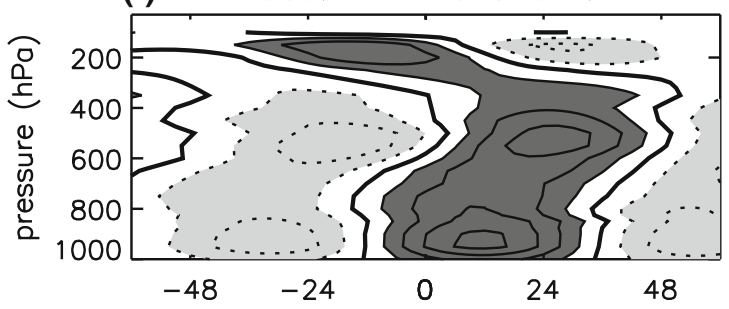

(h) TRMM Rainfall anom.

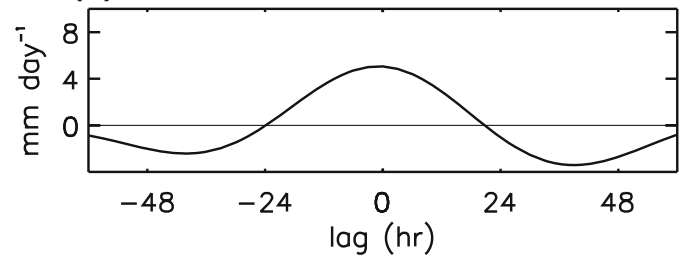

$(\mathbf{g}, \mathbf{h})$. Contour increments for temperature, moisture, and winds are: $3.75 \times 10^{-2} \mathrm{~K}, \quad 6.75 \times 10^{-2} \mathrm{~g} \mathrm{~kg}^{-1}$, and $1.25 \times 10^{-1} \mathrm{~ms}^{-1}$, respectively

deviations of $P_{\mathrm{ew}}$ during June though August at a base point in the western north Pacific $\left(135^{\circ} \mathrm{E}, 12.5^{\circ} \mathrm{N}\right)$, where easterly waves are active in both the model and observations. Taking these standard deviations as thresholds, we estimate on the basis of Fig. 17 that roughly 50\% more storms are generated from easterly waves in the model as compared to observed (139 vs. 93). Focusing on the western and eastern north Pacific, the biases are even larger at roughly $100 \%$ (117 vs. 57 ) and $81 \%$ (47 vs. 26 ), respectively, while a roughly $90 \%$ deficit (2 vs. 24 ) is found over the tropical north Atlantic.

In spite of these deficiencies, good agreement is found between composites of simulated versus observed TC genesis, constructed for storms whose development is 
(a) WRF $T$ anom. (138E, 12.5N)

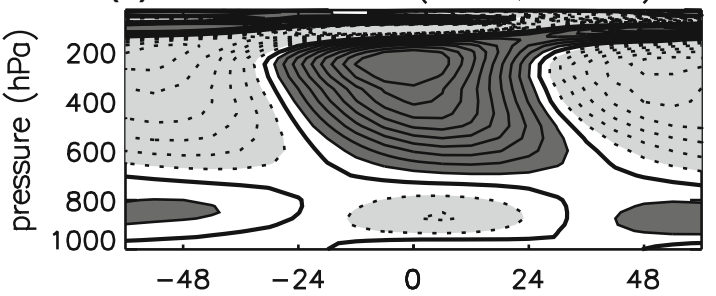

(c)

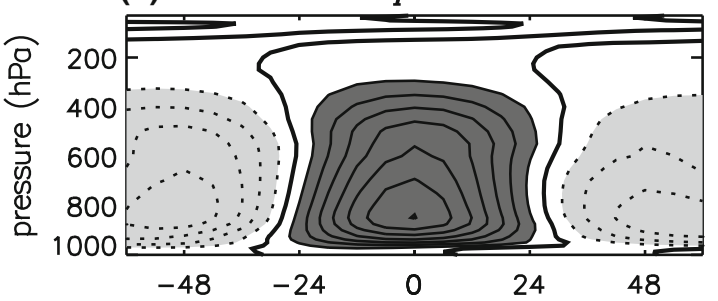

(e) WRF $v$-wind anom.

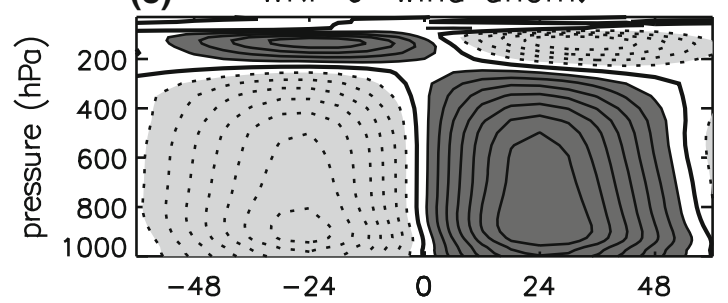

(g) WRF Rainfall anom.

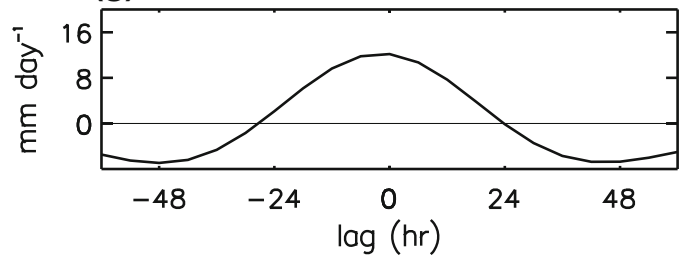

Fig. 14 Similar to Fig. 13 , but for the base points: $138^{\circ} \mathrm{E}, 12.5^{\circ} \mathrm{N}$ (left panels) and $138^{\circ} \mathrm{E}, 9.5^{\circ} \mathrm{N}$ (right panels). Observational results are based on twice-daily sounding data at Yap. Contour increments

objectively linked to easterly waves. Figure 18 shows that genesis in both the model and observations coincides with the arrival of a large-scale, westward-moving envelope of precipitation; the envelope's speed of translation is initially around $8-9 \mathrm{~ms}^{-1}$, but then decreases to around $6-7 \mathrm{~ms}^{-1}$, at the time of genesis. Looking at the low-level (700-hPa) flow in the envelope's moving frame of reference (as in Wang et al. 2008), Figure 19 shows that genesis in both the model and observations occurs near the center of a closed gyre circulation, with predominantly westerly flow on the gyre's southern and western flanks. More precisely, genesis occurs near the intersection of the disturbance's $700-\mathrm{hPa}$ trough axis and the zero-relative-flow isopleth.

This behavior is consistent with the "marsupial" paradigm of TC genesis from easterly waves, recently proposed by Dunkerton et al. (2009). As its name suggests, the (b) Obs. $T$ anom. (138E, 9.5N)

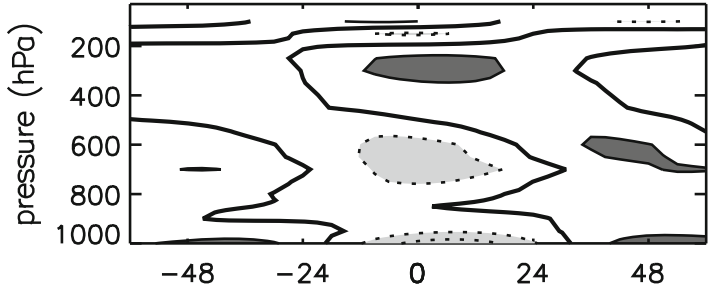

(d)

Obs. $q$ anom.

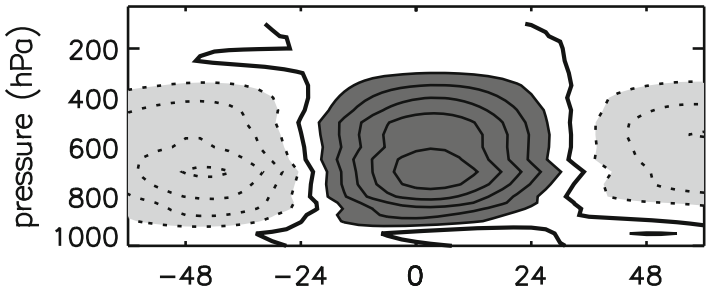

(f) Obs. $v$-wind anom.

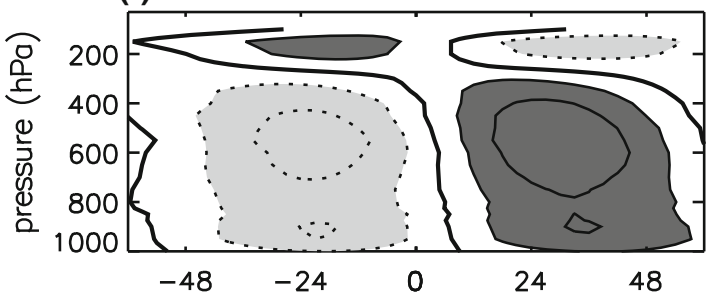

(h) TRMM Rainfall anom.

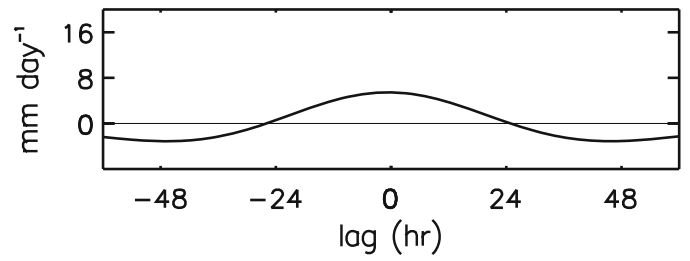

for temperature, moisture, and winds are: $7.5 \times 10^{-2} \mathrm{~K}$, $6.75 \times 10^{-2} \mathrm{~g} \mathrm{~kg}^{-1}$, and $3.75 \times 10^{-1} \mathrm{~ms}^{-1}$, respectively

marsupial paradigm envisions the closed gyre circulation of an easterly wave critical layer as being especially favorable for TC genesis, by protecting the incipient storm from the detrimental effects of horizontal mixing and straining, analogous to a joey inside a mother kangaroo's pouch. This protection is thought to provide a window for the buildup of vorticity on the TC-scale (mainly through diabatic processes), until the storm has reached sufficient amplitude to survive on its own. However, the marsupial paradigm is basically silent as to the precise timing of TC genesis.

To address this issue, we employed a low-pass Lanczos filter with a cutoff period of 20 days to construct composites of the TC-genesis environment at $700 \mathrm{hPa}$. Figure 20 shows that genesis in each of the three basins occurs when the simulated/observed wave disturbance enters the 
(a) WRF 700-hPa stream func. and winds at lag 0

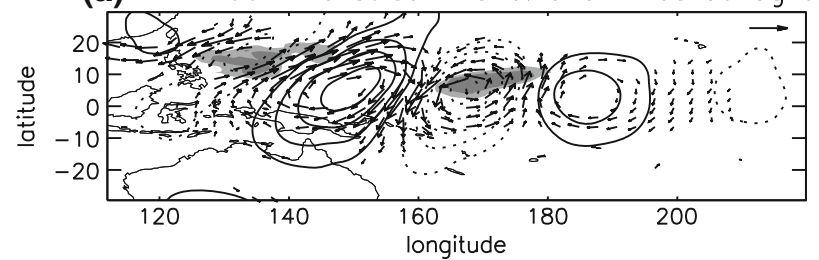

(b) JRA 700-hPA stream func. and winds at lag 0

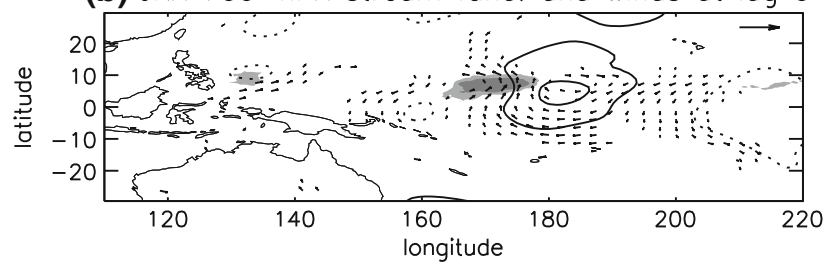

(c) WRF $700-\mathrm{hPa}$ stream func. and winds at lag 0

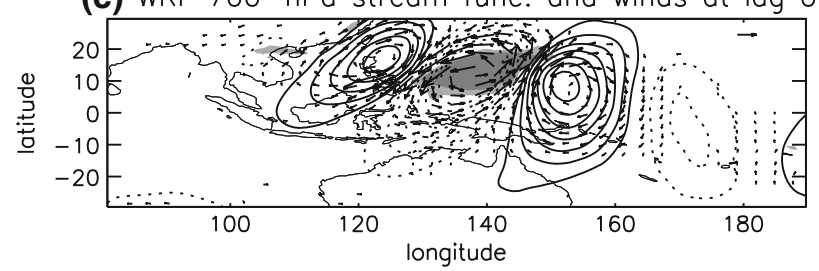

(d) JRA 700-hPA stream func. and winds at lag 0

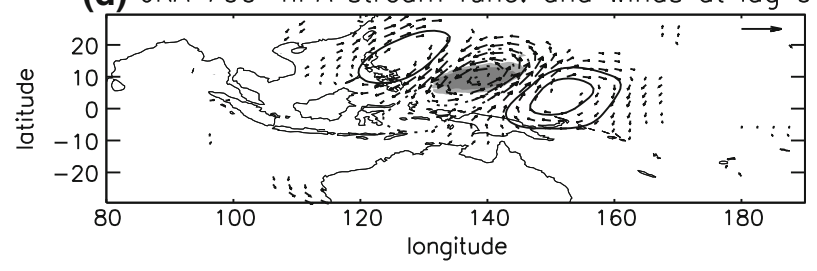

Fig. 15 Regressed horizontal dynamical structures of easterly waves in the model $(\mathbf{a}, \mathbf{c})$ and Japanese Reanalysis data $(\mathbf{b}, \mathbf{d})$. Results in the top (bottom) two panels are for base points in the central (western) Pacific; see Fig. 11. Plotting convention is similar to Fig. 10, except that solid (dotted) contours denote positive (negative) values of the horizontal stream function, with increments of $1 \times 10^{5} \mathrm{~m}^{2} \mathrm{~s}^{-1}$. Wind vectors at upper right in each panel denote a wind speed of $1 \mathrm{~ms}^{-1}$

exit-region of an easterly jet, where the zonal derivative of the background zonal flow is strongly negative (i.e., $d U / d x$ $\ll 0$ ). Over the west Pacific, there is also a westerly jet to the south and west of the base point, which further contributes to $d U / d x$ being negative. These results are consistent with Holland (1995)'s idea that TC genesis from easterly waves is ultimately caused by the disturbance entering a region of stretching deformation, where $d U / d x$ $\ll 0$, such that wave energy is enhanced on small scales via "wave accumulation" (Webster and Chang 1988). Similar evidence for wave accumulation playing an important role in TC genesis can be found in the recent WRF study by Done et al. (2009).

\section{Summary and discussion}

This study examined the performance of the WRF tropical channel model in simulating two types of synoptic tropical weather disturbances: convectively-coupled Kelvin and easterly waves. Generally good agreement was found between the simulated and observed wave structures and their evolution, suggesting that the model is able to capture the basic dynamics of the phenomena. However, the climatologies of both wave types were found to be deficient, with easterly waves being much too active over the Pacific (but relatively inactive elsewhere) and Kelvin waves being relatively inactive throughout the tropics, especially over South America, Africa, and the Atlantic. Errors in the model's easterly wave climatology were seen to directly impact the simulated frequency of TC genesis, with too many storms developing from easterly waves over the north Pacific, and too few over the north Atlantic. Still the kinematics of the wave-to-TC-genesis process appear to be well simulated, with evidence for both wave accumulation and critical layer processes being importantly involved.

Overall, results of this study suggest that convection in the model is coupling too strongly to rotational circulation anomalies. This interpretation is further supported by Fig. 21, which compares zonal averages from $100^{\circ} \mathrm{E}$ to $180^{\circ} \mathrm{E}$ of the temporal correlation between daily, coarsegrained $\left(2.5^{\circ} \times 2.5^{\circ}\right)$ rainfall and $850-\mathrm{hPa}$ vorticity in the model versus observations, given by the solid and dotted
Fig. 16 Histograms of TC genesis events versus latitude for the model (solid) and "besttrack" observations (dotted) over the western and eastern north Pacific and the north Atlantic (a-c, respectively). The total number of simulated/ observed genesis events within each basin are indicated next to the corresponding histogram

TC Genesis vs. Latitude 2000-2005 (WRF vs. Best Track)

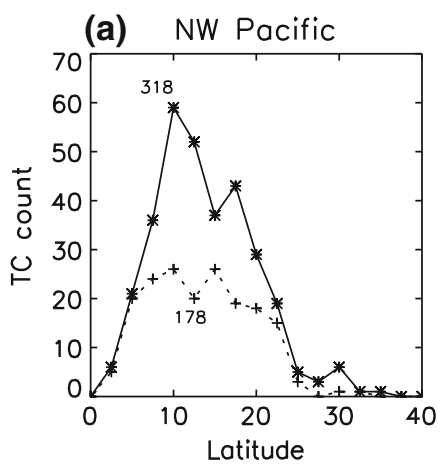

(b) NE Pacific

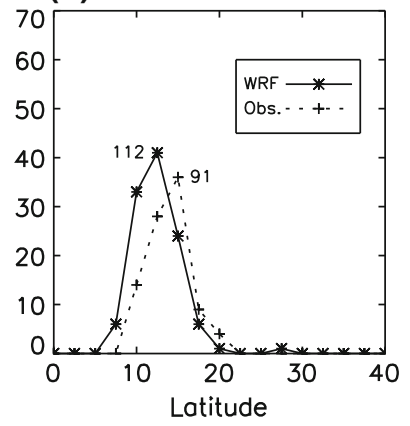

(c) N Atlantic

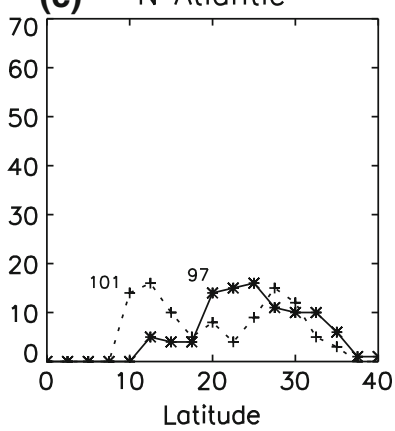


(a) WRF TC count vs. $P_{\text {ew }}(2000-2005)$

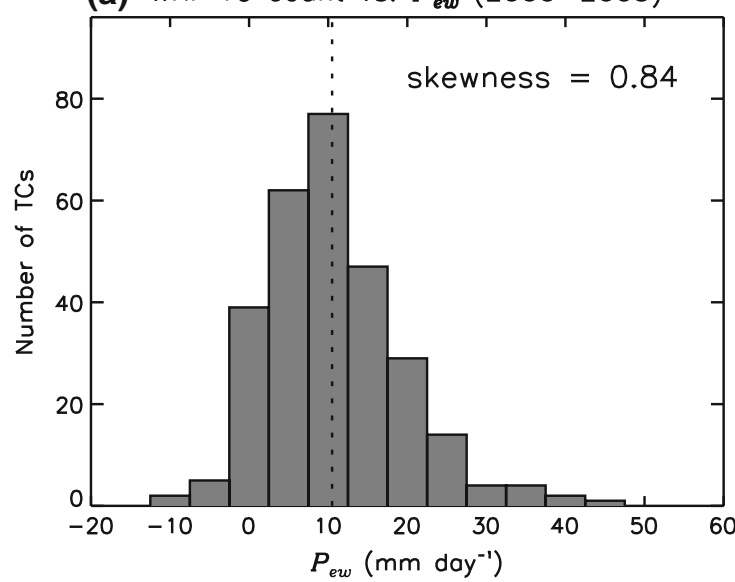

Fig. 17 Histograms of coarse-grained $\left(5^{\circ} \times 5^{\circ}\right)$ easterly-wave-filtered rainfall $\left(P_{\mathrm{ew}}\right)$ calculated for the genesis locations and times of all a simulated and $\mathbf{b}$ observed TCs that developed between $0^{\circ}$ and

(a) WRF TC genesis rain composite

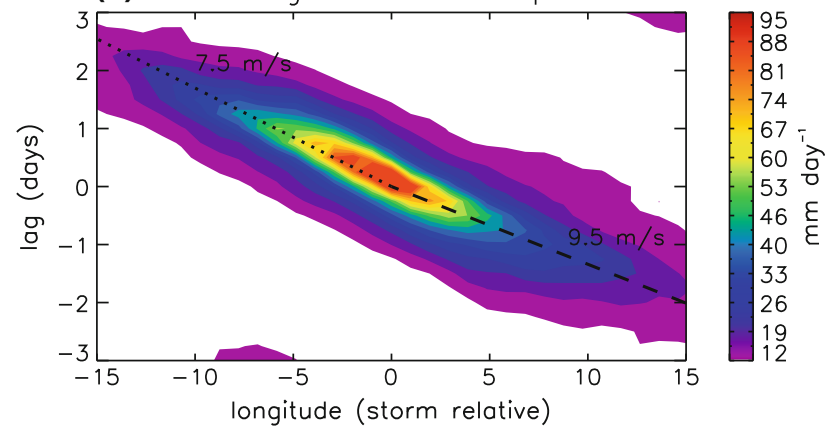

(b) TRMM TC genesis rain composite

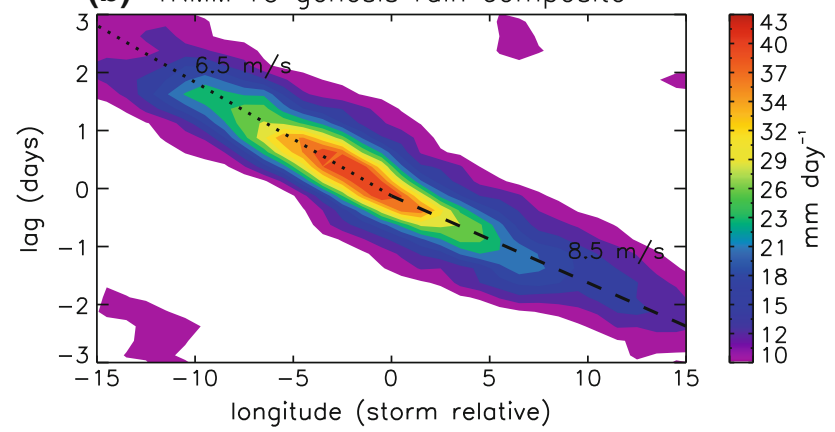

Fig. 18 Composite evolution of rainfall relative to TC genesis in the a model and $\mathbf{b}$ observations. Composites were constructed for storms whose development is objectively linked to easterly waves based on Fig. 17 (see text for details). Rainfall was averaged over a $5^{\circ}$-wide latitude band centered on the genesis point. Dashed (dotted) lines in a and $\mathbf{b}$ denote phase speeds of 9.5 and $8.5 \mathrm{~ms}^{-1}$ (7.5 and $6.5 \mathrm{~ms}^{-1}$ ), respectively

curves, respectively. Although the distributions appear broadly similar (with generally larger amplitudes at higher latitudes), the magnitudes of the correlations are generally around 50\% larger in the model as compared to observed. Interestingly, a similar (but weaker) type of bias is found in (b) Obs. TC count vs. $P_{e w}(2000-2005)$

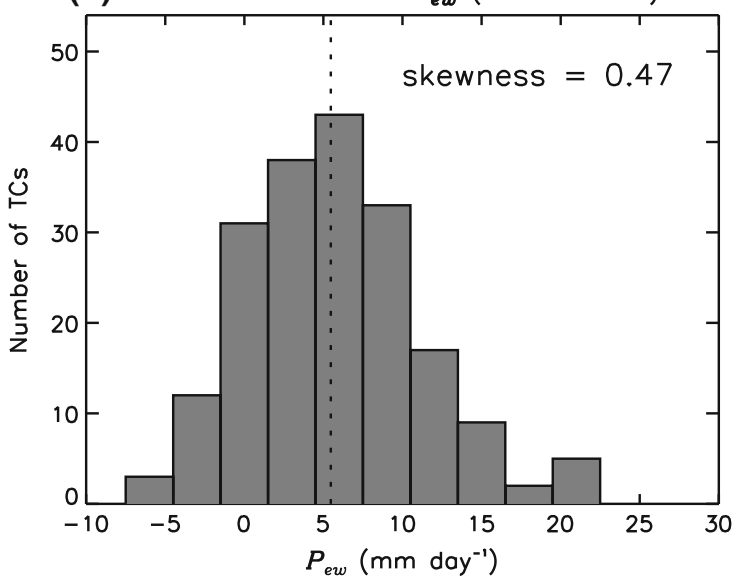

$15^{\circ} \mathrm{N}$ in either the north Pacific or Atlantic. Dashed lines denote objective thresholds for linking easterly waves to TC genesis (see text for details). Observed values of $P_{\mathrm{ew}}$ were obtained using TRMM data

(a) WRF TC genesis composite (lag 0)

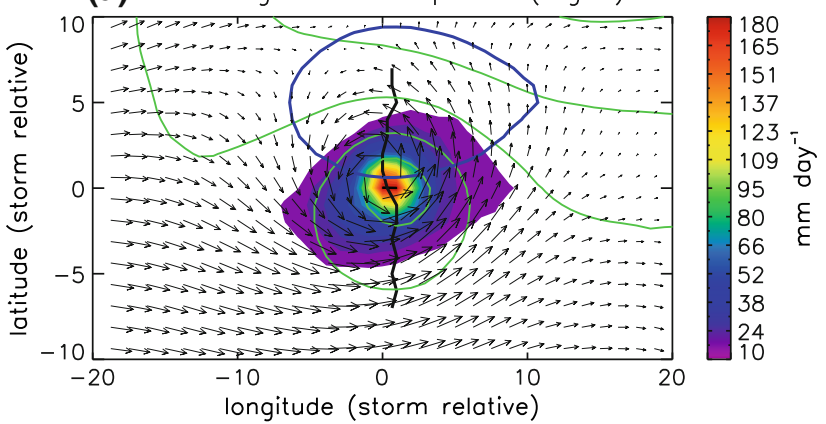

(b) Obs. TC genesis composite $(\log 0)$

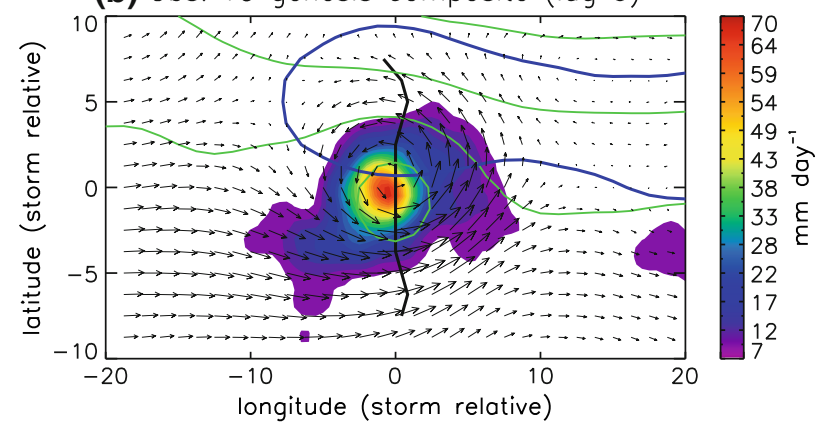

Fig. 19 TC-genesis composites at lag 0 of the a simulated versus b observed 700-hPa flow (wind vectors) in a frame of reference moving with the corresponding rain envelopes of Fig. 18, together with the geopotential height field (green contours) and the zero-relative-flow isopleth (heavy blue curve). Heavy black curve denotes the disturbance's trough axis. The speeds of the Lagrangian reference frames are $\mathbf{a} 7.5$ and $\mathbf{b} 6.5 \mathrm{~ms}^{-1}$

the SP-CAM, as illustrated by the dashed line in Fig. 21 (data provided by M. Khairoutdinov). Whether this implied overly tight coupling between convection and low-level rotation is a cause or a consequence of these two models' tendency to produce too much rain at off-equatorial latitudes is not yet clear. 
TC-genesis background flow composites (700 hPa)
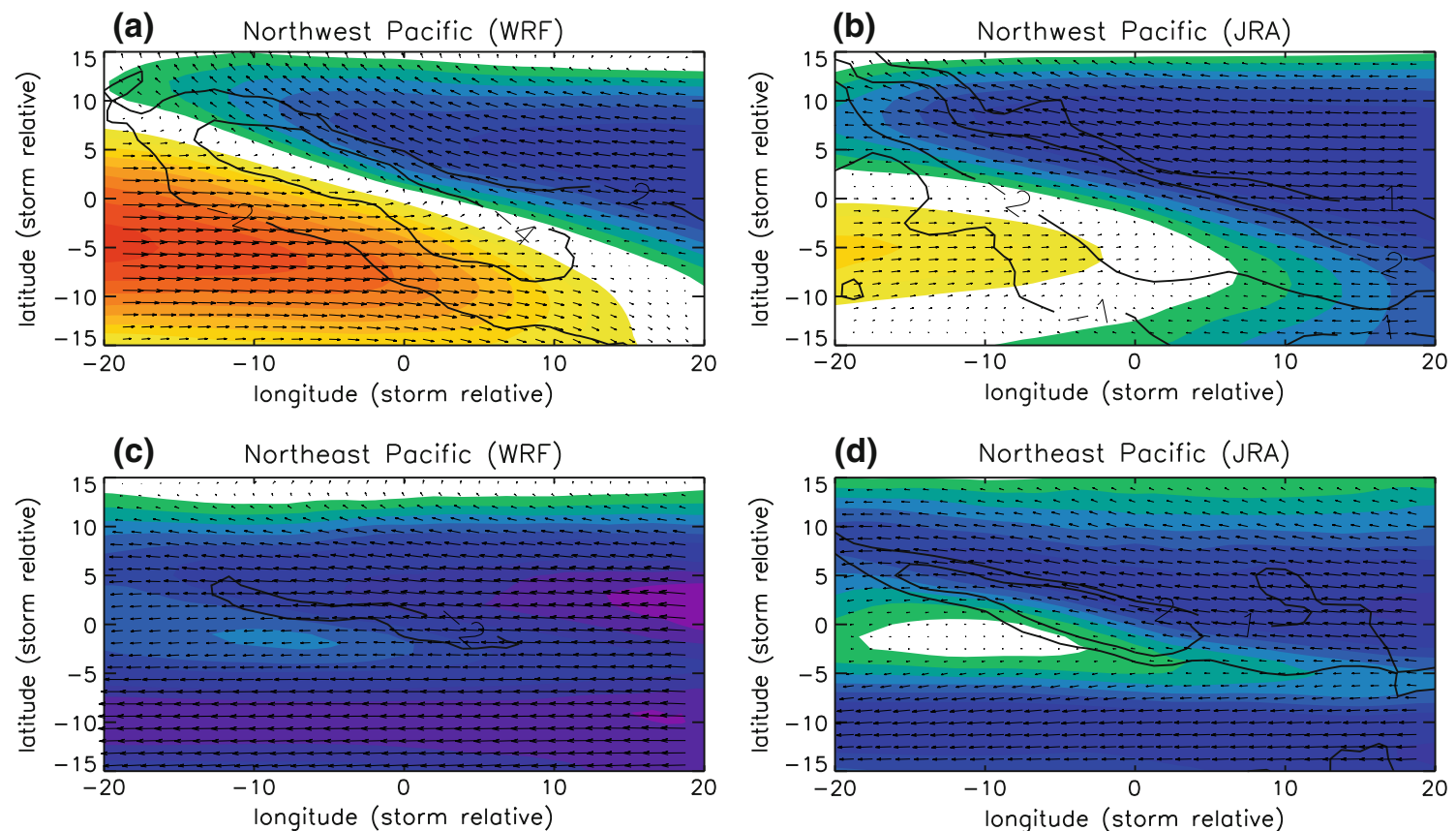

(d)

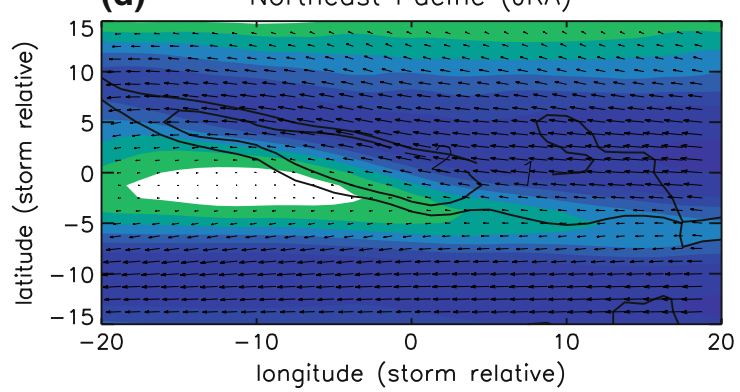

(c)

North Atlantic (WRF)
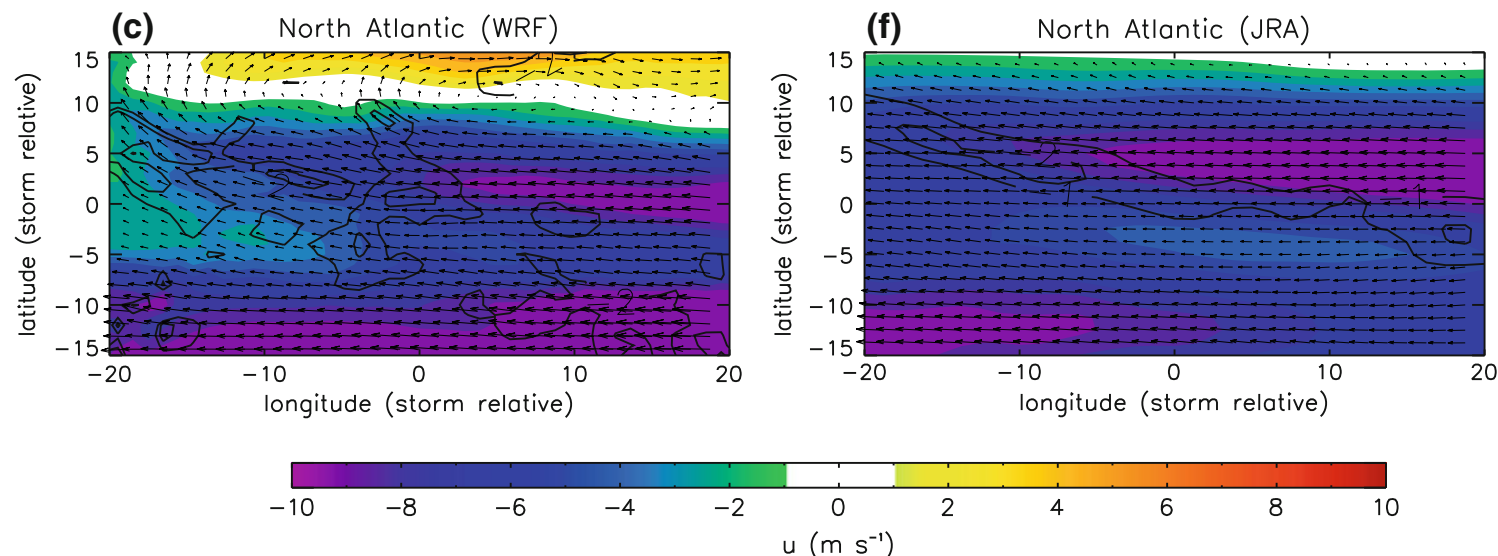

Fig. 20 Composites of the 700-hPa background flow relative to TC genesis at lag 0 in the model (left column) and Japanese Reanalysis (right column), constructed for storms in the northwest Pacific (top), northeast Pacific (middle) and north Atlantic (bottom). Shading

Many of this study's findings are similar to those of Yang et al. (2009), who examined convective variability in two Hadley Centre climate models (HadAM3 and HiGAM) with very different dynamical cores, but similar horizontal grid spacings $(\sim 100 \mathrm{~km})$. In particular, their analysis showed that tropical convection in both models tends to preferentially couple to westward-propagating Rossby-type wave disturbances, as opposed to eastward-propagating Kelvin modes, which apparently results in synoptic-scale convection variability being heavily biased towards offequatorial latitudes, especially over the tropical warm pool region. denotes the zonal component of the flow, while contours denote negative values of the zonal derivative of the zonal flow (with units of $1 \times 10^{-5} \mathrm{~s}^{-1}$ )

In conclusion, a similar pattern of tropical biases (in both a time-mean and/or time-varying sense) can be found across a broad range of contemporary high-resolution climate models, as well as the superparameterized versions of the low-resolution CAM and the NASA fvGCM. This similarity is reminiscent of the double-ITCZ problem found in many low-resolution, coupled-ocean-atmosphere models (e.g., Kim et al. 2008). However, while the doubleITCZ problem appears mainly over the central and eastern Pacific, where meridional gradients in SST are relatively large, here the biases are most prominent over the western Pacific and Indian Ocean basins, where meridional 


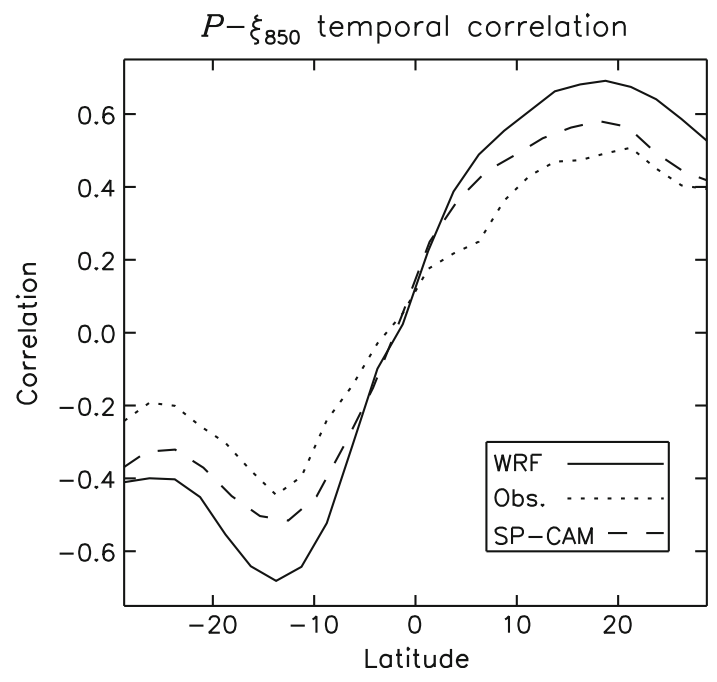

Fig. 21 Zonal averages from $100^{\circ} \mathrm{E}$ to $180^{\circ} \mathrm{E}$ of the temporal correlation between daily, coarse-grained $\left(2.5^{\circ} \times 2.5^{\circ}\right)$ rainfall and $850-\mathrm{hPa}$ vorticity in the model versus observations, given by the solid and dotted curves, respectively. The dashed curve is similar, but for output from the SP-CAM, described in Khairoutdinov et al. (2008)

gradients in SST are relatively weak. We anticipate that further diagnosis of these tropical biases will shed light on the model modifications needed to improve the representation of convection variability in next-generation climate models.

Acknowledgments Dr. Tulich was supported by a visiting postdoctoral appointment at the National Center for Atmospheric Research. Mrs. Suzuki-Parker acknowledges the support of the World Bank, Chevron, and the Research Partnership to Secure Energy for America (RPSEA). The reanalysis data were provided from the cooperative research project of the JRA-25 long-term reanalysis by the Japan Meteorological Agency (JMA) and the Central Research Institute of Electric Power Industry (CRIEPI). Archived output from the SP-CAM was provided graciously by Prof. Marat Khairoutdinov. This manuscript was improved through comments by Prof. Brian Mapes and one anonymous viewer.

\section{References}

Bengtsson L, Hodges KI, Esch M, Keenlyside N, Kornblueh L, Lou JJ, Yamagata T (2007) How may tropical cyclones change in a warmer climate. Tellus A 59:539-561

Caron JM (2009) The Madden Julian oscillation in the nested regional climate model. Clim Dyn (submitted)

Chang C-P (1970) Westward propagating cloud patterns in the tropical Pacific as seen from time-composite satellite photographs. J Atmos Sci 27:133-138

Chauvin F, Royer J-F, Deque M (2006) Response of hurricane-type vortices to global warming as simulated by ARPEGE-Climat at high resolution. Clim Dyn 27:377-399

Chen T, Wang S, Yen M, Clark A (2008) Are tropical cyclones less effectively formed by easterly waves in the western north Pacific than in the north Atlantic? Mon Weather Rev 136:4527-4540

Cherchi A, Navarra A (2007) Sensitivity of the Asian summer monsoon to the horizontal resolution: differences between
AMIP-type and coupled model experiments. Clim Dyn 28: 273-290

Derbyshire SH, Beau I, Bechtold P, Grandpeix J-Y, Piriou J-M, Redelsperger J-L, Soares PMM (2004) Sensitivity of moist convection to environmental humidity. Q J R Meteorol Soc 130:3055-3079

Done J, Holland G, Suzuki-Parker A, Webster PJ (2009) The role of wave energy accumulation in tropical cyclone genesis over the tropical north Atlantic. Clim Dyn (submitted)

Dunkerton TJ., Montgomery MT, Wang Z (2009) Tropical cyclogenesis in a tropical wave critical layer: easterly waves. Atmos Chem Phys 9:5587-5646

Ferranti L, Palmer TN, Molteni F, Klinker E (1990) Tropicalextratropical interaction associated with the 30-60 day oscillation and its impact on medium and extended range prediction. J Atmos Sci 47:2177-2199

Frank WM, Roundy PE (2006) The role of tropical waves in tropical cyclogenesis. Mon Weather Rev 134: 2397-2417

Fuchs Z, Raymond DJ (2007) A simple, vertically resolved model of tropical disturbances with a humidity closure. Tellus A 59: 344-354

Hendon HH, Liebmann B, Newman M, Glick JD (2000) Mediumrange forecast errors associated with active episodes of the Madden-Julian oscillation. Mon Weather Rev 128:69-86

Holland G (1995) Scale interaction in the western pacific monsoon. Meteorol Atmos Phys 56:57-79

Holland GJ, Hurrel JM et al (2009) The NCAR nested regional climate model. Clim Dyn (in preparation)

Holton JR (1971) A diagnostic model for equatorial wave disturbances: the role of vertical shear of the mean zonal wind. J Atmos Sci 28: 55-64

Huffman GJ et al (2007) The TRMM multisatellite precipitation analysis (TMPA): quasi-global, multiyear, combined-sensor precipitation estimates at fine scale. J Hydrometeorol 8: $38-55$

Kain JS (2004) The Kain-Fritcsh convection parameterization: an update. J Appl Meteorol 43:170-181

Kain JS, Fritsch JM (1993) Convective parameterization for mesoscale models: the Kain-Fritsch scheme. In: The representation of cumulus convection in numerical models, no. 24 in Meteorol Monogr. AMS, pp 170-181

Khairoutdinov M, DeMott C, Randall D (2008) Evaluation of the simulated interannual and subseasonal variability in an AMIPstyle simulation using the CSU multiscale modeling framework. J Cim 21:413-431

Khairoutdinov M, Randall D, DeMott C (2005) Simulations of the atmospheric general circulation using a cloud-resolving model as a superparameterization of physical processes. J Atmos Sci 62: 2136-2154

Khouider B, Majda AJ (2006) A simple multicloud parameterization for convectively coupled tropical waves. Part I: linear analysis. J Atmos Sci 63:1308-1323

Kiladis GN, Thorncroft CD, Hall NMJ (2006) Three-dimensional structure and dynamics of African easterly waves. Part I: observations. J Atmos Sci 63:2212-2230

Kim H-J, Wang B, Ding Q (2008) The global monsoon variability simulated by CMIP3 coupled climate models. J Clim 21:52715294

Kuang Z (2008) A moisture-stratiform instability for convectively coupled waves. J Atmos Sci 65: 834-854

Kuang Z (2009) Linear response functions of a cumulus ensemble to temperature and moisture perturbations and implication to the dynamics of convectively coupled waves. J Atmos Sci (in press)

Landsea CW (1993) The climatology of intense (or major) Atlantic hurricanes. Mon Weather Rev 121:1703-1713 
Lau K-H, Lau N-C (1990) Observed structure and propagation characteristics of tropical summertime synoptic-scale disturbances. Mon Weather Rev 118: 1888-1913

Lau N-C, Ploshay JJ (2009) Simulation of synoptic and sub-synoptic scale phenomena associated with the east Asian summer monsoon using a high-resolution GCM. Mon Weather Rev 137:137-160

Liebmann B, Kiladis GN, Carvalho LM, Jones C, Vera CS, Blade I, Allured D (2009) Origin of convectively coupled Kelvin waves over South America. J Clim 22:300-315

Lin J-L et al (2006) Tropical intraseasonal variability in 14 IPCC AR4 climate models. Part I: convective signals. J Clim 19:26652690

Madden RA, Julian PR (1994) Observations of the 40-50-day tropical oscillation-a review. Mon Weather Rev 122:814-837

Magnusdottir G, Wang C-C (2008) Intertropical convergence zones during the active season in daily data. J Atmos Sci 65:1497-1512

Mapes B, Tulich S, Lin J, Zuidema P (2006) The mesoscale convection life cycle: building block or prototype for large-scale tropical waves? Dyn Atmos Oceans 42:3-29

Mapes BE (2000) Convective inhibition, subgrid-scale triggering energy, and stratiform instability in a toy tropical wave model. J Atmos Sci 58:517-526

Mapes BE, Tulich SN, Nasuno T, Satoh M (2008) Predictability aspects of global aqua-planet simulations with explicit convection. J Meteorol Soc Jpn 86A: 175-185

Mekonnen A, Thorncroft CD, Aiyyer AR, Kiladis GN, (2008) Convectively coupled Kelvin waves over tropical Africa during the boreal summer: structure and variability. J Clim 21:66496667

Miura H, Satoh M, Nasuno T, Noda A, Oouchi K (2007) A MaddenJulian Oscillation event simulated using a global cloud-resolving model. Science 318:1763-1765

Nguyen KC, McGregor JL (2009) Modelling the Asian summer monsoon using CCAM. Clim Dyn 32:219-236

Onogi K et al (2007) The JRA-25 reanalysis. J Meteorol Soc Jpn 85:369-432

Oouchi K, Yoshimura J, Yoshimura H, Mizuta R, Kusunoki S, Noda A (2006) Tropical cyclone climatology in a global-warming climate as simulated in a $20 \mathrm{~km}$-mesh global atmospheric model: frequency and wind intensity analysis. J Meteorol Soc Jpn 84:259-276

Ratnam JV, Giorgio F, Kaginalkar A, Cozzini S (2009) Simulation of the indian monsoon using RegCM3-ROMS regional coupled model. Clim Dyn 33:119-139

Ray P, Zhang C, Moncrieff MW, Dudhia J, Caron JM, Leung R, Bruyere C (2009) The role of the mean state on the initiation of the Madden-Julian oscillation. Clim Dyn (submitted)

Reed RJ, Norquist DC, Recker EE (1977) The structure and properties of African wave disturbanes as observed during Phase III of GATE. Mon Weather Rev 105:317-333

Reed RJ, Recker EE (1971) Structures and properties of synopticscale wave disturbances in the equatorial western Pacific. J Atmos Sci 28:1117-1133

Ricciardulli L, Sardeshmukh PD (2002) Local time- and space scales of organized tropical deep convection. J Clim 15:2775-2790

Ringer $M$ et al (2006) The physical properties of the atmosphere in the new Hadley Centre Global Environmental Model (HadGEM1). Part II: aspects of variability and regional climate. J Clim 19:1302-1326

Roundy PE, Frank WM (2004) A climatology of waves in the equatorial region. J Atmos Sci 61:2105-2132
Serra YL, Kiladis GN, Cronin MF (2008) Horizontal and vertical structure of easterly waves in the Pacific ITCZ. J Atmos Sci 65:1266-1284

Shapiro LJ (1978) The vorticity budget of a composite African tropical wave disturbance. Mon Weather Rev 106:806-817

Slingo JM et al (1996) Intraseasonal oscillations in 15 atmospheric general circulation models: results from an AMIP diagnostic subproject. Clim Dyn 12:325-357

Sobel AH, Bretherton CS (1999) Development of synoptic-scale disturbances over the summertime tropical northwest Pacific. J Atmos Sci 56:3106-3127

Straub KH, Haertel PT, Kiladis GN (2009) An analysis of convectively coupled Kelvin waves in 20 WCRP CMIP3 global coupled climate models. J Clim (submitted)

Straub KH, Kiladis GN (2002) Observations of a convectively coupled Kelvin wave in the eastern Pacific ITCZ. J Atmos Sci 59:30-53

Straub KH, Kiladis GN (2003) Extratropical forcing of convectively coupled Kelvin waves during austral winter. J Atmos Sci 60:526-543

Takayabu YN, Murakami M (1991) The structure of super cloud clusters observed in 1-20 June 1986 and their relationship to easterly waves. J Meteorol Soc Jpn 69:105-125

Tao W-K et al (2009) A multi-scale modeling system: developments, applications and critical issues. Bull Am Meteorol Soc 90:515534

Tulich SN, Mapes BE (2008) Multiscale convective wave disturbances in the tropics: insights from a two-dimensional cloudresolving model. J Atmos Sci 65:140-155

Tulich SN, Mapes BE (2009) Transient environmental sensitivities of explicitly simulated tropical convection. J Atmos Sci (accepted)

Tulich SN, Randall DA, Mapes BE (2007) Vertical-mode and cloud decomposition of large-scale convectively coupled gravity waves in a two-dimensional cloud-resolving model. J Atmos Sci 64:1210-1229

Walsh KJE, Nguyen K-C, McGregor JL (2004) Fine-resolution regional climate model simulations of the impact of climate change on tropical cyclones near Australia. Clim Dyn 22:47-56

Wang Z, Montgomery MT, Dunkerton TJ (2008) A dynamicallybased method for forecasting tropical cyclogenesis location in the Atlantic sector using global model products. Geophys Res Lett 36(L03081). doi:10.1029/2008GL035586

Webster PJ, Chang H-R (1988) Equatorial energy accumulation and emanation regions: impacts of a zonally varying basic state. J Atmos Sci 45:803-829

Wheeler M, Kiladis GN (1999) Convectively coupled equatorial waves: analysis of clouds and temperature in the wavenumber frequency domain. J Atmos Sci 56:374-399

Wheeler M, Kiladis GN, Webster PJ (2000) Large-scale dynamical fields associated with convectively coupled equatorial waves. J Atmos Sci 57:613-640

Wheeler M, Weickmann KM (2001) Real-time monitoring and prediction of modes of coherent synoptic to intraseasonal tropical variability. Mon Weather Rev 129:2677-2694

Xie SP, Xu H, Saji NH, Wang Y, Liu WT (2006) Role of narrow mountains in large-scale organization of Asian monsoon convection. J Clim 19:3420-3429

Yang G-Y, Slingo J, Hoskins B (2009) Convectively coupled equatorial waves in high resolution Hadley Centre climate models. J Clim 22:1897-1919 